\title{
Die Panzerhaut der Weichschildkröte Emyda granosa und die funktionelle Bedeutung ihrer Strukturen.
}

\author{
Von
}

Prof. Dr. W. J. Scbmidt in Bonn (Zoolog. Institut).

Hierzu Tafel XIII und XIV und 8 Textabbildungen.

Inhaltsübersicht: Seite

Einleitung . . . . . . . . . . . . . . . 186

Die bisherigen Angaben über den Bau der unverknöcherten Haut der

Schildkröten . . . . . . . . . . . . . . . . . . . . . . . 189

I. Der Bau der Lederhaut.

1. Die histologischen Elemente der Lederhaut. . . . . . . 193

2. Die Architektur der Lederhaut . . . . . . . . . . . 195

a) Bündelschicht . . . . . . . . . . . . . . . 196

b) Filzschicht . . . . . . . . . . . . 203

c) Verhalten der verschiedenen Schichten mit Rüclisicht auf die Schale als Ganzes . . . . . . . . . . . . . . . 204

II. Der Bau der Oberhaut . . . . . . . . . . 210

III. Die Epidermis-Kutisverbindung . . . . . . . 216

IV. Die funktionelle Bedeutung des Aufbaues der Panzerhaut .................... 224

\section{Einleitung.}

Emyda granosa Schoepff (subsp. vittata Ptrs. = E. ceylonensis aut.) gehört jener Familie der Chelonier an, die nach den wulstigen Kieferanhängen die Lippenschildkröten, nach den dreikralligen Füssen die Trionychiden heisst und die im Gegensatz zu fast allen übrigen Schildkröten (Ausnahme Dermochelys) durch den Mangel von Hornschild ern auf dem Panzer ausgezeichnet ist. Dass das Fehlen der genannten Hautelemente kein ursprünglicher Zustand ist, geht, abgesehen von allgemeinen Erwägungen über die Phylogenie der Schildkröten (vgl. Versluys 1914), aus der Tatsache hervor, dass bei manchen Trionychiden - und so auch bei Emyda granosa - auf dem Rückenschild Erhebungen vorkommen, die den morphologischen Wert von Schuppen besitzen (G o e t te 1899, Sch midt 1920), meist in der Jugend besser ent- 
wickelt sind, mit zunehmendem Alter einer Rück- oder Umbildung anheimfallen und damit ganz unscheinbar werden. Abgesehen von diesen Schuppenrudimenten und einer undeutlich körnigen Skulptur, die, durch das Oberfiächenrelief des darunter liegenden Knochens bedingt, nur der Rückenmitte und einzelnen Stellen der Bauchseite (über den sog. "Callositäten" des knöchernen Bauchschildes) eigen ist und dem Tier zu einem Speziesnamen verholfen hat, erscheint bei Emyda granosa die Oberfläche glatt und ungefeldert. Dabei erlangt die Hornschicht der Epidermis bei den Trionychiden weder die Festigkeit noch die Dicke wie das "Schildpatt" der übrigen (thekophoren) Schildkröten, sondern ist dünn und so weich, dass man mit dem Fingernagel in ihr Eindrücke hervorrufen kann.

Der knöcherne Panzer der Trionychiden ist schwach entwickelt: die am Aufbau des Bauchschildes (Plastron) beteiligten Stücke schliessen zeitlebens grössere, von unverknöcher tem Bindegewebe erfüllte Lücken zwischen sich ein; im Rückenschild (Carapax) bilden die mit den oberen Bögen der Wirbel verschmolzenen Neuralplatten und die anschliessenden mit den Rippen vereinten Costalplatten eine Scheibe (Diskus), die sich auf den mittleren Teil des Rückens beschrankt, so dass ein ziemlich breiter ha utiger Saum ringsum bestehen bleibt, in dem bei Emyda granosa und einigen anderen Arten isolierte Randknochen (Marginalia) liegen. D i ese unverknöcherten Anteile des Panzers (daher die Bezeichnung Weichschildkröten), die beim jugendlichen Tier verhältnismässig umfangreicher sind als beim erwachsenen, machen den Gegenstand der folgenden Untersuchung aus. Gemass den vorigen Angaben stehen Rücken- und Bauchschild seitlich nur in hautigem Zusammenhang und lassen eine vordere Schalenöffnung frei, aus der Kopf und Vorderbeine hervorgestreckt werden können, und eine hintere für die Hinterbeine; die letztere kann durch Anlegen der benachbarten, klappenartig abgesetzten Teile -des Bauchschildes nach Einziehen der Hinterextremitaten weitgehend verschlossen werden.

Die Trionychiden bewohnen als gewandte Schwimmer $z$ wischen den Zehen spannen sich Verbindungshäute aus und die Vorderbeine sind mit Flossensaumen versehen - die grossen Flüsse warmer und heisser Gebiete, daher auch Flußschildkröten genannt (gelegentlich dringen manche von ihnen ins Meer vor). 
Die starke Rückbildung des Knochenpanzers, die einer Verminderung des spezifischen Gewichtes gleichkommt, dürfte wie bei den Seeschildkröten im Zusammenhang mit dem Leben im Wasser entstanden sein.

Diese kurzen Angaben mögen hinreichen, auch einem mit den Schildkröten weniger vertrauten Leser die Züge der Organisation bei den Trionychiden wieder ins Gedăchtnis zu rufen, die für die folgende Untersuchung von Bedeutung sind.

Das benutzte Material wurde von den Herren DDr. F. und P. Sarasin in Ceylon gesammelt, an den verstorbenen Bonner Zoologen Prof. Ludwig abgegeben und von diesem mir zur Bearbeitung überwiesen. ${ }^{1}$ ) Den letzteren kann mein Dank nicht mehr erreichen, die Herren DDr. Saras in aber mögen versichert sein, dass ich bei der Untersuchung des vorzüglich konservierten Materials oft. ihrer vorbildlichen Forscher- und Sammeltätigkeit gedachte.

Die Tatsache, dass nur C. K. Hoffm an n $(1878,1890)$ und Ficalbi (1889) das Integument der Schildkröten mit ausgesprochener Rücksicht auf die histologischen Verhältnisse vorgenommen haben, liess eine erneute gründliche Bearbeitung des Gegenstandes wünschenswert erscheinen. Meine Absicht, eine allseitige Darstellung derselben zu geben, erfuhr durch die Kriegsverhältnisse eine langdauernde Verzögerung und Unterbrechung, so dass ich mich entschloss, hier nur einen der ins Auge gefassten Punkte genauer zu prüfen, nämlich den Bau des Panzers an den unverknöcherten Stellen. Einige Stichproben zeigten nämlich, dass der bindegewebige Teil der Schale einen erstaunlich regelmässigen, geradezu architektonischen Bau besitzt, von dem frühere Beobachter wesentliche Züge bereits erkannt haben, der aber keineswegs erschöpfend und in allen Punkten richtig geschildert wurde. Durch die strenge Gesetzmässigkeit seines Aufbaues verlockte das Objekt zu Betrachtungen über die fanktionelle Bedeutung dieser Strukturen.

Das Sarasi n sche Material umfasst eine Reihe nachembryonaler Altersstufen, deren kleinste $3,5 \mathrm{~cm}$, deren grösste $13,5 \mathrm{~cm}$

1) Auch meine Veröffentlichungen im Zoolog. Anz.: „Über den dermalen Ursprung der Neuralplatten bei den Schildkröten“ 1916 und „Über Schuppenrudimente und Hautsinnesorgane bei Emyda granosa" 1920 fussen auf S a r as in schem Material. 
misst. (Die Grössenangaben beziehen sich auf die Länge des Bauchschildes.) Die Tiere waren, eröffnet, im ganzen (in Chromsäure?) fixiert und in reichlichem starken Alkohol aufgehoben. Sie erwiesen sich trotz der Länge der Zeit als ganz vorzüglich erhalten und insbesondere war das Integument auch für feinste histologische Untersuchungen brauchbar. Vornehmlich habe ich grössere Exemplare (über $10 \mathrm{~cm}$ Länge) zur Úntersuchung benutzt. Zum Studium der Verflechtung des Bindegew ebes im Korium bediente ich mich solcher Schnitte, die mit dem Rasiermesser freihändig hergestellt wurden, was bei der knorpelartigen Konsistenz der unverknöcherten Stellen des Panzers sehr leicht gelingt. Ungefärbt in Balsam eingebettet und bei geeigneter Abblendung betrachtet, geben sie infolge der hohen Lichtbrechung der kollagenen Fasern sehr übersichtliche Bilder (vgl. Taf. XIII). Da die Schnitte für den genannten $Z$ weck nicht zu dünn sein dürfen, um z. B. die aufsteigenden Fasern durch die ganze Dicke des Integuments hindurch verfolgen zu können, so ist eine Färbung überflüssig, weil dịe Schnitte nur dunkler werden, obne für diese Gesichtspunkte Neues erkennen zu lassen. Zur Untersuchung der his tologischen Einzelheiten, insbesondere der Verbindung von Epidermis und Kutis, waren dünne Mikrotomschnitte, bis $8 \mu$ herab, notwendig, die sich bei den jüngeren Exemplaren leichter gewinnen liessen als bei den alteren. Sie wurden mit Heidenhains Eisenbamatoxylin in Verbindung mit Eosin oder Pikrinsänre-Säurefuchsin nach van Gieson gefarbt.

\section{Die bisherigen Angaben über den Bau der unverknöcherten Haut der Schildkröten.}

Im folgenden Abschnitt sollen die bisher vorliegenden Angaben über das unverknöcherte Integument der Chelonier Platz finden, soweit sie für unseren Zweck von Bedeutung sind.

Dass ein so auffallender Bau, wie ihn die Haut der Trionychiden zeigt, auch früheren Beobachtern nicht entgehen konnte, ist selbstverständlich. Unter der Fülle von Mitteilungen, die H. Rathke (1848) in seinen Untersuchungen äber die Entwicklung der Schildkröten bringt, finden sich auch die ersten genaueren Angaben über das Integument dieser Tiere. Rathke unterscheidet an ihnen das Unterhautbindegewe be und die Lederh a t oder das eigentliche Korium, eine Einteilung, deren vergleichend anatomische Richtigkeit später geprüft werden soll (s. S.208f.). Während Cuvier und nach ihm andere glaubten, die bei unvollständiger Verknöcherung im tarapax und Plastron vorhandenen Lücken seien von einer knorpeligen 
Substanz ausgefüllt, erkannte $R$ athke, dass es sich hier um ein „Unterbautbindegewebe ${ }^{a}$ von ganz ungewöhnlicher Dichtigkeit, Festigkei $仑$ und Dicke handle. Nicht nur seine faserigen Bestandteile beschreibt er treffend, sondern ex erwähnt auch zwischen ihnen eine formlose, durch Essigsäure lösliche Substanz, die nach unseren heutigen Kenntnissen nichts andere darstellt als die mucinhaltige Kittmasse, welche die kollagenen Bündel vereinigt.

$R$ athke bemerkt, dass das "Unterhautbindegewebe" schon bei reifen Embryonen eine ziemlich grosse Dicke hat, die im nachembryonalen Leben zunächst noch steigt, am beträchtlicbsten bei Seeschildkröten und bei Trionyx ist und hier vor der Fertigstellung der Knochenplatten einen ziemlich schwer durchdringbaren Panzer bildet. Durch das Wachstum des Knochenpanzers in Fläche und Dicke wird das Unterhautbindegewebe allmählich verdrängt, aber dort, wo dauernd Liicken im Panzer bleiben, nimmt es an Dicke zu.

Die eigentliche L ederhaut, dünner als das Unterhautbindegewebe, besteht nach $\mathrm{R}$ ath ke aus schichtenweise - bei Trionyx ocellatus zähite der Autor bis acht solcher Schichten - geordneten Bindegewebsbündeln, die aus sehr zarten Fasern zusammengesetzt sind. In jeder Schicht haben sie dieselbe Verlaufsrichtung, kreuzen sich aber hei benachbarten. Rathke, der auch bei anderen niederen Wirbeltieren (Cyklostomen, Haien, Stören, Knochenfischen, Sauriern, Schlangen, Krokodilen) die gekreuzte Anordnung der Faserschichten des Koriums fand, weist darauf hin, dass sie eine Ausdehnung der Haut nach verschiedenen Richtungen gestattet. Doch ist seine Angabe, dass die Bündel einiger Schichten ziemlich genau nach der Länge des Rumpfes verlaufen, die übrigen aber quer über denselben, für die Trionychiden und wohl die Schildkröten überhaupt, auch nach meinen Erfabrungen für andere Reptilien irrig (s. S. 196). Nicht jede Schicht reicht über den ganzen Rücken oder Banch, denn bei Chelone virgata beobaclitete $R$ athlie, dass eine zwischen $z$ wei anderen endigte, während diese sich zu einer einzigen vereinigten. Das kommt nach 'meinen Beobachtungen auch bei $\mathrm{Em} \mathrm{yda}$ vor. Innerhalb der einzelnen Schichten sollen bei Trionyx, Platemys, Terrapene keine deutlichen Verbindungen benachbarter Bündel statthaben, während sie bei Chelone sich hänfig unter sehr spitzen Winkeln in zwei Äste spalten die in zunächst benachbarte Bündel derselben Schicht übergehen oder sich auch wieder miteinander vereinen, so dass zwischen ihnen hier und da langgestreckte Maschen vorkommen. Im Gegensatz zu $R$ athke finde ich aber das letztbeschriebene Verhalten auch bei Emyda ganz ausgesprochen.

Die Anwesenheit der die horizontalen Lagen durchbohrenden, anfsteigenden Fasern ist $\mathrm{R} a \mathrm{th} \mathrm{ke}$ entgangen, und damit hängt es zusammen, dass er der Koriumschicht unmittelbar unter der Epidermis eine ganz andere Beschaffenheit als im übrigen zuspricht: ${ }_{n}$ Sie besteht. nämlich nicht aus Bündeln von Bindegewebe, sondern aus kurzen einzelnen Fasern, die entweder einfach oder auch gabelförmig gespalten sind und teils sich nur aneinanderlegen, teils auch ineinander übergehen, überhaupt aber ein kleingefenstertes Gewebe zusammensetzen ...." (S. 148 a.a. 0.)

Bei der Ausdehnung des Knochenpanzers in die Dicke bleibt schliesslich nur die gefensterte Schicht zurück. Bei einem halbwüchsigen Trionyx 
ferox bestand die Lederhaut auf den Knochen des Rïcken- und Bauchschildes noch aus einer einfachen Schicht paralleler Faserbündel; bei einem Trionyx granosus (= Emyda granosa) fehlten die Faserbündel auf den einzelnen kleinen Erhöhungen des Rückenschildes, waren aber zwischen denselben deutlich vorhanden. Bei demselben Trion y x fanden sich an unverknöcherten Stellen sechs bis acht Schichten von Faserbündeln; hier erwähnt $R$ ath $\mathrm{ke}$ (a. a. O. S. 149) auch neben der formlosen durch Essigsäure löslichen Masse sparsame rundliche Körper, „Primitivzellen“, so dass er die drei Bestandteile des kollagenen Bindegewebes, Zellen, Fasern und Kittsubstanz, wohl unterschieden hat.

An Hals, Beinen und Schwanz ist bei jungen Schildkröten die Haut im allgemeinen zwar dünner als am Rumpf; doch weist das Korium hier ebenfalls eine Zusammensetzung aus mehreren kreuzschichtigen Lagen von Faserbündeln auf. Bei Trionyx ferox zählte $\mathrm{R}$ ath ke an Hals und Beinen bis sechs solcher Schichten (S. 149). Wenn der Autor (S. 153) sagt, bei erwachsenen Schildkröten sei die Lederhaut an Hals, Schwanz und Beinen dicker als auf dem Rücken- und Bauchschild, so kann das nur für die verknöcherten Stellen Geltung haben, an denen die oben erwähnte Reduktion eingetreten ist.

Die Angaben Rathkes über die Histologie der Epidermis sind für uns weniger von Bedeutung. Es sei nur erwähnt, dass die Hornzellen ohne wahrnehmbare Verbindungen fest zusammenllängen sollen, dass der Autor (neben braunem und schwarzem) bei Pentonyx capensis dunkel olivgriines Pigment in der Epidermis sah (auch die Guanophoren der Kutis kennt er bei' Emys europaea als Zellen mit hellem körnigen Pigment).

Leider sind Rathkes Ausführnngen über das Integument nicht von Abbildungen begleitet; trotz der eindringlichen Art der Darstellung, die dem glänzenden Beobachter eigentümlich ist, dürften sie daher für manchen Leser, der mit den einschlägigen Verhältnisssn wenig vertraut ist, schwer verständlich sein, und der Mangel an Abbildungen scheint mir auch die Ursache dafür, dass diese Mitteilungen $R$ athkes in der späteren einschlägigen Literatur nicht die rechte Würdigung gefunden haben.

C. K. H off man n (1878, S. 153-158; mit geringfügigen Änderungen und unter Beigabe einiger neuer Abbildungen kehren die Angaben 1890, S. 3-8, wieder) untersuchte junge Exemplare von Chelonia, Sphargis coriacea, Testudo, Emys, Trionyx aufs Integument. Nach seiner Auffassung ist die von L e ydig für die Reptilien vorgeschlagene Gliederung der Lederhaut in die "Grundmasse" aus derben wagerechten Lagen und die jene beiderseits einfassenden locker gewebten „Grenzschichten" bei Schildkröten schwer zu erkennen, wie überhaupt ein allgemeines Bild vom Bau der Lederhaut nicht leicht zu entwerfen. Am eigentïmlichsten findet er den Aufbau an Bauch und Rücken vom jungen Trion yx: zunächst unter der Epidermis mehr oder weniger parallel verlaufende wagerechte Bündel, die nach innen zu allmählich dicker werden, dann die von $R a t h k e$ heschriebenen rechtwinklig gekreuzten 14-18 Schichten derber Bündel, deren jedes aus äusserst feinen Fasern zusammengesetzt ist, die durch eine Kittmasse verbunden sind, darauf 
eine lockere gefässreiche Bindegewebslage aus wellenförmig verlaufenden, einander kreuzenden Fasern ( $R$ a th kes Unterhautbindegewebe) und schliesslich eine Schicht mehr oder minder parallel ziehender Fasern. Von der lockeren Schicht setzen sich einige Fasern als senkrechte Züge in die oberhalb and unterhalb gelegenen Schichten fort und verbinden so die verschiedenen miteinander. Die Lederhaut stimmt also fast vollständig mit derjenigen der Selachier gemäss den Untersuchungen O. Hertwigs (1874) überein. Am Hals ist bei Trionyx das Korium sehr dünn und zeigt unmittelbar unter der Epidermis eine Schicht lockeren Bindegewebes, dann dickere Bündel, die sich nach verschiedenen Richtungen kreuzen und endlich wiederum eine lockere Lage; das Unterhautbindegewebe erwies sich reich an elastischen Fasern.

Bei Sphargis fand Hoffmann die Fasern des Koriums der Schale nach allen Richtungen verwoben und nur unmittelbar unter der Epidermis und zu innerst mehr oder weniger parallel verlaufend, im Flossensaum dagegen eine mehr an Trionyx erinnernde, wenn auch nicht so regelmässige Anordnung der Fasern. Am Hals kreuzten sich die Bündel untereinander in sehr spitzen Winkeln, deren Lücken von anderen dazu senkrecht stehenden durchsetzt werden. Ähnlich wie Sphargis verhält sich Chelonia.

Die Malpighische Schicht der Epidermis besteht nach $H$ of $f$ $\mathrm{mann}$ aus e in er Lage zylindrischer Zellen mit fein grauuliertem Plasma (Rückenhaut junger Trion ychiden 1890, S. 3) oder es folgen bis auf die Hornschicht noch mehrere Reihen allmällich sich abflachender Zellen. Die Hornschicht zeigt auf dem Querschnitt eine feine regelmässige Streifung, ihre Zellen in Flächenansicht eine feine Granulierung, die der Autor als sehr zarte, spitz zulaufende Stachelchen deuten möchte. Doch stellt Hoffmann bei Lippen-, Lurch-, Süsswasser- und Landschildkröten das Vorkommen von „Riff- und Stachelzellen“ in Abrede; dagegen sah er bei Seeschildkröten in den mittleren Lagen der Epidermis die Konturen der Zellen durch äusserst kleine, stark lichtbrechende Kügelchen begrenzt.

E. Fic albi (1889), der das Integument von 'I'estudo graeca und Emys lutaria (= Cistudo europaea) einer eingehenden Prüfung unterzogen hat. glaubt für diese Formen die Leydigsche Einteilung der Lederhaut (s. o.) in gleicher Weise wie bei den anderen Reptilien durchführen zu können. Besonderen Wert für uns besitzen Ficalbis Angaben über die Verbindung von Epidermis und Kutis. Die basalen Zylinderzellen der Epidermis erscheinen an ihrer Basis (vor allem dort, wo die Haut verknöchert ist) stark gezähnelt und pflanzen sich mit bald längeren, bald kürzeren Fortsätzen der Hant ein; die Zähne können aber auch fehlen. Eine hyaline B a s a $1 \mathrm{~m}$ e m bra n der Epidermis existiert nicht, vielmehr bleibt ihre Struktar immer faserig und geht kontinuierlich in das daruntergelegene Bindegewebe über. Sind die Zähnchen sehr lang, so bilden sie eine wenig gefärbte Zone, welche der Gesamtheit der Zähne und der spärlichen dazwischen gelegenen Bindesubstanz entspricht und eine Basalmembran vortäuscht; bald aber ruhen die Zähne unmittelbar auf der lockeren Bindegewebeschicht, bald findet sich zwischen den Zühnen und der eben ge- 
nannten lockeren Lage eine $\operatorname{spongiöse~} B$ indesubstanz, die sich wenig färbt und in der die Zähne ilren Ursprung nehmen. Die letzte Art der Verbindung sieht Ficalbi als die typische an; sie sei besonders deutlich an den pigmentierten Stellen der Haut, wo sie als ein * straterello connettivo sottoepidermicos Chromatophorenlage und Epidermis trennt.

Wenn auch nicht überall und oft schwierig, so kann Ficalbi doch stellenweise die „Zähnchen" (Zellbrücken) der Zellen im S trat u m Ma lpighi i erkennen. Die Hornschicht erscheint oft aus zwei bis drei übereinander gelegenen Lagen zusammengesetzt, die (auch durch die Pigmentrerteilung gesondert) den sonst bei der Häutung abgeworfenen Abschnitten entsprechen. Somit stellt das Schildpatt nicht eine einzige, stark entwickelte Hornschicht, sondern eine Vereinigung vieler Hornschichten dar, die hier nicht, wie an anderen Stellen des Körpers, abgeworfen werden. An der mächtigen Hornlage über den verknöcherten Hautpartien (bei Testudo graeca) sieht man über der Malpighi schen Schicht eine mehr oder minder körnige Zone, entsprechend dem von $L$ w of $f$ beschriebenen Stratum granulosum in der Haut der Krokodile. Eine strukturlose äussere Abgrenzung der Epidermis fehlt.

Schliesslich entiehme ich noch Goette (1899) einige Angaben über die Entwicklung der Haut. Bei $1 \mathrm{~cm}$ langen Embryonen von Chelone imbricata ist der Panzer in seiner ganzen Dicke unter der Epidermis von einem sehr lockeren, nicht geschichteten oder verfilzten, sondern bloss netzartigen Bindegewebe auśgefüllt, das zwischen den Rippen bis zum Bauchfell vordringt. Unmittelbar unter der Epidermis wird das Bindegewebe dichter und dunkler; an der Bauchwand sind in dieser Zone bereits die Anlagen der Plastronstücke sichtbar und demnach bezeichnet Goette diese Schicht als Katis, das darunter gelegene lockere Gewebe als subkutanes Bindegewebe. Im Laufe der Entwicklung fält nach Goette das subkutane Bindegewebe ganz ausserordentlich zusammen; es wird aber wahrscheinlich nicht einfach nnterd̈rückt, sondern in die vordringende Kutis aufgenommen; es erfolgt also eine Verdickung der Kutis auf Kosten des unterliegenden Gewebes.

\section{Der Bau der Lederhaut.}

\section{Die histologischen Elemente der Lederhaut.}

Die Lederhaut des Panzers von Emyda granosa gliedert sich in zwei Lagen, die ich von aussen nach innen fortschreitend als Bündel- und Filzschicht bezeichnen werde; der Betrachtung ihrer Architektur seien ein paar Worte über ihren wesentlichen Bestandteil, das kollagene Bindegewebe, vorausgeschickt.

Seine typischen Elementarbestandteile, die Zellen, die leimgebenden Fasern und die jene verbindende Grundoder Kittmasse treten besonders in der locker gebauten Filzschicht übersichtlich hervor (Fig. 33, Taf. XIV). 
Die Zellen (Fibroblasten) sind plasmaarm, von wechselnder Form, den gegebenen Raumverhältnissen angepasst, bald mehr, bald weniger verästelt; ihr $\mathrm{Kern}$ ist kugelig oder ellipsoidal, $z$ wischen den Lagen der Bündelschicht abgeplattet, oft stäbchenförmig, wobei die Langsachse mit der Verlaufsrichtung der kollagenen Fasern zusammenfällt. In der Năhe des Kernes findet sich ein aus zwei kleinen, dicht beieinander gelegenen Körnchen bestehendes Zentriol (Diplosom, Fig. 34, Taf. XIV, Fibroblast aus dem lockeren Bindegewebe der Lippen).

Die leimgebenden Bündel wechseln ihre Dicke beträchtlich, je nach der Schicht, welcher sie angehören. Die „Elementarfibrillen", welche sie aufbauen, sind aber stets sehr fein und bieten sich daher selbst unter hohen Vergrösserungen in Langsansicht als zarte Streifung, quer getroffen als entsprechende Punktierung dar. Sehr dicken Faserbündeln liegen die Zellen nicht nur auf, sondern dringen auch in ihr Inneres ein, so dass eine Gliederung in Teilbündel erfolgt.

Den zwischen Zellen und Fasern verbleibenden Raum erfüllt die Grundsubstanz (Kittmasse); nach H offmann (s. o.) soll sie auch die Elementarfibrillen in den einzelnen Bündeln miteinander verkleben; doch konnte ich sie hier nicht sicher wahrnehmen. In den locker gebauten Teilen der Haut, vor allem in der Filzschicht, kann die interfibrillare Substanz an Masse; Zellen und Fasern bei weitem übertreffen (Fig. 33, Taf. XIV) und tritt bei Tinktion mit. Delafields Hämatoxylin nebst Eosin durch ihren kräftig blauen Ton $z u$ den rot gefarbten leimgebenden Fasern in auffallenden Gegensatz. Bekanntlich beruht diese Eigentümlichkeit der Kittmasse auf ihrem Gehalt an $\mathrm{Mucin}$ (vgl. auch oben bei Rathke). Verhăltnismässig reichlich erscheint die Grundmasse auch in den unmittelbar an die Epidermis anschliessenden Teilen der Lederhaut, dagegen auf ein Mindestmass beschränkt, wo die kollagenen Bündel fest aufeinander gepresst sind.

Der Nachweis elastischer Fasern glückte weder mit Resorzinfuchsin noch mit Orcein; sie scheinen somit im Bereich der unverknöcherten Schale zu fehlen, was nicht verwunderlich wăre, weil sie sich dort zu finden pflegen, wo Gewebemassen grösseren Deformationen ausgesetzt sind, was für den Panzer nicht zutrifft. 
Ausser den eigentlichen Elementen des kollagenen Bindegewebes besitzt die Lederhaut noch verschiedene Einlagerungen, die für die mechanischen Leistungen des Panzers von untergeordneter Bedeutung sind: Melanophoren, Guanophoren, noch einige andere, an Wanderzellen erinnernde Zellen, ferner $\mathrm{N}$ erve $\mathrm{n}$ und Bl u tg efässe. Die schwarzen Pigmentzellen kommen nur der Rückenhaut zu (Fig. 1, Taf. XIII), in der sie nahe der Epidermis eine ziemlich lockere Schicht liefern, aber auch spärlicher und in charakteristischer Verzweigung in den übrigen Lagen der Lederhaut auftauchen. Unmittelbar unter der Epidermis und zwar in der Haut des Rückenschildes über den Melanophoren also in der bei den Reptilien allgemein üblichen Anordnung finden sich die guaninführenden Zellen, deren starke Entwicklung auf der Bauchseite wesentlich zu ihrer weisslichen Färbung beitrăgt (über die feinere Beschaffenheit der Guanophoren vgl. W. J. Schmidt 1917, S. 203, s. auch oben bei Rathke und Ficalbi). Blutgefässe (V) und Nerven (N) bilden in der Filzschicht (Fig. 9, Taf. XIII) - im Rückenschild oft von Melanophoren umscheidet (diese Zellen halten die Richtungen geringsten Widerstandes im Gewebe ein, v. Prowazek) - weitmaschige Netze, die an einzelnen Stellen durch die Bündelschicht hindurch Zweige entsenden, die sich unter der Oberhaut in ăhnlicher Form plexusartig ausbreiten.

\section{Die Architektur der Lederhaut.}

An einem senkrechten Durchschnitt aus dem unverknöcherten Randgebiet von Rücken- oder Bauchschale (Textfig. A, S. 197) einer erwachsenen Emyda lassen sich schon mit unbewaffnetem Auge Rathkes (s. o.) eigentliches Korium und Unterhautbindegewebe unterscheiden. Jenes unmittelbar auf die dünne Epidermis folgend, auf der Schnittflache von sehnigem Glanz, ist unsere $B$ ündelschicht die daran anschliessende Lage unserer Filzschicht; die letztere erfahrt an ihrer Unterflache eine Verdichtung zu einer Grenzschicht. Die Dicke der Bündelschicht betrăgt bei einem Exemplar von $13,5 \mathrm{~cm}$ Länge $0,64 \mathrm{~mm}$, die der Filzschicht 2,4 mm (auf die Grenzschicht entfallen hiervon 0,3 mm), alles gemessen an der Haut des Bauchschildes; rechnet man noch die Dicke der Epidermis mit rund $0,1 \mathrm{~mm}$ hinzu, so ergibt sich für die Gesamtdicke der Haut etwas über $3 \mathrm{~mm}$. 
a) Bündelschicht.

Betrachtet man die Bündelschicht am Durchschnitt der Haut unter schwächerer Vergrösserung oder mit unbewaffnetem Auge, so erscheint sie verschieden, je nach dem Verlauf des Schnittes mit Rücksicht auf die Symmetrieverhältnisse der Schale. Geht er nämlich von rechts nach links oder von vorn nach hinten, also senkrecht zur Hauptsymmetrieebene oder parallel zu ihr, so gewahrt man in der Bündelschicht eine Anzahl von Lagen annähernd parallel zur Oberfläche der Haut, aber nur mässig deutlich voneinander geschieden. Verläuft der Schnitt dagegen von rechts hinten nach links vorn, oder links hinten nach rechts vorn, somit unter einem Winkel von annahernd $45^{\circ}$ zur Hauptsymmetrieebene, so wechselt das Aussehen der aufeinander folgenden Lagen aufs schärfste. Schnittbilder der letzten Art, diagonale Querschnitte mögen sie kurz (im Gegensatz zu den erst genannten orthogonalen) heissen, sollen den Ausgangspunkt der Untersuchung bilden.

Die einzelnen Lagen der Bündelschicht bestehen aus sehr kräftigen kollagenen Bündeln, die innerhalb der gleichen Lage parallel geordnet, von Lage $z$ u Lage aber um $90^{\circ}$ gegeneinander gekreuzt sind. Da nun im diagonalen Querschnit (Fig. 1 und 2, Taf. XIII), der eine Teil der Bündel (L) mit seiner Längsfaserung in die Schnittebene hineinfallt, der andere (Q) aber senkrecht getroffen wird, so muss die Verlaufsrichtung der Bündel mit den beiden di agon a len Richtungen der Schale übereinfallen. Die längs geschnittenen Bündel (L) zeigen eine leicht wellige Streifung nnd zarte Faserung, die auf ihre Zusammensetzung aus Teilbündelchen und Elementarfibrillen beruht, ausserdem eine undeutliche vertikale Streifung, deren Wesen spater erörtert wird. Die Mehrzahl der Bündel besitzt einen bandartig abgeplatteten Querschnitt ( $Q$, und zwar stehen die einzelnen Bündel einer Lage auf der Kante und sind, nur durch schmale Raume voneinander getrennt, dicht aneinander gereiht. Würde man die Schnittrichtung um $90^{\circ}$ gegen die den Abbildungen zugrunde gelegte ändern, so vertauschen die-Schichten ihr Aussehen, indem die vorher längs getroffenen nunmehr zu quer geschnittenen werden und umgekehrt; das Gesamtbild erfăhrt dadurch natürlich keine wesentliche Umgestaltung. 
Die verschiedenen Lagen der Bündelschicht sind an einel gegebenen Stelle des Querschnittes nicht ron gleicher Dicke, sondern nehmen sowohl nach oben, zur Epidermis, als auch nach unten, zur Filzschicht hin, an Stärke ab. (Fig. 1 und 2, Taf. XIII.) Und wenn man die gleiche Lage über eine gewisse Strecke hin verfolgt, so ergibt sich, dass ihr Verlauf keineswegs der Hautoberflache parallel geht, sondern dass sie unter sehr spitzem Winkel gegen die Epidermis emporsteigt. (Textfig.A.) So wird eine Schicht, die an einer Stelle die unterste ist, an einer anderen schliesslich zur obersten, und mit dieser $\ddot{A} n d e-$ rung des Niveaus we chselt auch die Dicke der betreffenden, Lage: sie beginnt sehr dünn an der Filzschicht, nimmt gegen die Oberhaut ansteigend allmählich an Stärke zu, erreicht etwa in der Mitte der Bündelschicht ihr Maximum, etwa $100 "$, um weiterhin gegen die Epidermis sich wieder zu verjüngen und schliesslich ganz fein auszulaufen. Um dieses Verhalten klar. zu erkennen, ist es nötig (unter schwachen Objektiven, etwa unter einem Binokularmikroskop), e inen etwas grösseren Abschnitt der Haut zu überschauen (Textfig. A), obwohl auch

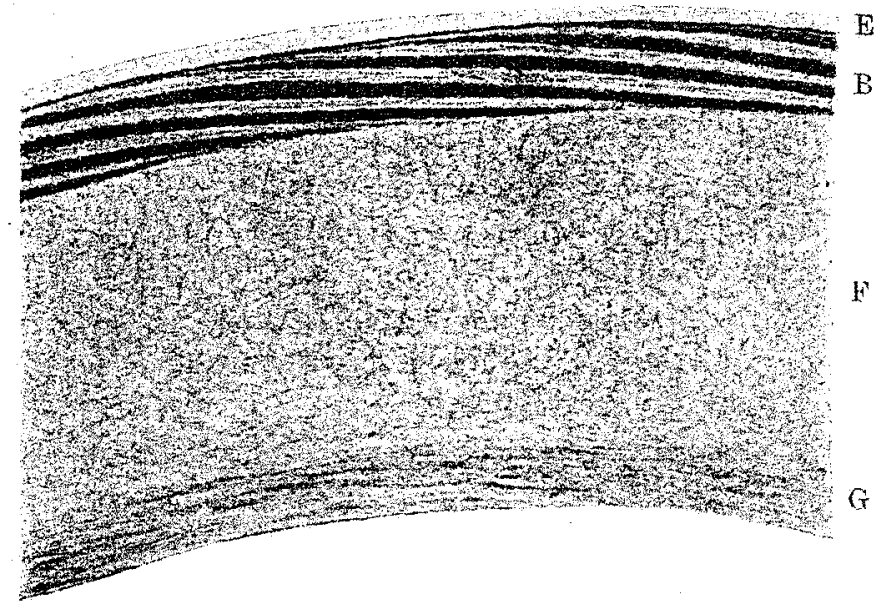

Textfigur A.

Diagonaler Querschnitt durch die unverknöcherte Hant der Bauchschale einer $13,5 \mathrm{~cm}$ langen Emyda.

E Epidermis, B Bündelschicht, F Filzschicht, G Grenzschicht. Vergr. 16:1. Man beachte den Verlauf der einzelnen Lagen der Bündelschicht. 
bei aufmerksamer Betrachtung z. B. del Fig. 2 (Taf. XIII) leicht ersichtlich ist, dass alle Schichten der Bündellage von links nach rechts gegen die Oberhaut emporsteigen und dass die unterste längsgetroffene Lage nach links, die oberste (unmittelbar unter der Guaninschicht) nach rechts verjüngt auslauft. .

Die Lagen der Bündelschicht reichen bis unmittelbar an das Epithel heran; es besteht somit zwischen Epidermis und Bündelschicht keine besondere Lage des Koriums, wie Rathke und Hoffmann wollten. Nur insoweit erführt das Verhalten der Bündel eine Änderung gegenüber der Mitte, als unmittelbar unter dem Epithel die Bündel innerhalb derselben Lage und auch die benachbarten Schichten durch reichliche Kittmasse voneinander getrennt sind, und die Querschnitte der kollagenen Bündel daher mehr rundliche Gestalt annehmen (Fig. 3, Taf. XIII), worauf später noch genauer eingegangen werden soll. Im untersten Niveall der Bündelschicht (vgl. Fig. 1, Taf XIII) werden die einzelnen Bündel einer lage durch die hier noch dicken senkrecht aufsteigenden Fasern voneinander abgedrängt (s. u.).

Ist man über die Lage eines Hautstückchens zur Schale im ganzen unterrichtet, so ergeben $\mathrm{Flachschnitte}$ durch die Bündelschicht zunächst eine unmittelbare Bestatigung der am diagonalen Querschnitt gewonnenen Anschauung, dass die Faserrichtung der einzelnen Lagen $\pm 45^{\circ}$ zur Hauptsymmetrieebene orientiert ist; ferner zeigen sie obne weiteres, dass die Lagen sich ibwechselnd rechtwinklig kreuzen (vgl. Fig. 7, Taf. XIII). Fassen wir zunächst einen Flachschnitt durch das mittlere Niveau der Bündell a ge genauer ins Auge, der so geführt ist. 'dass er gerade eine Lage der Bündel enthält, wie es bei deren erheblicher Stärke und einem einigermassen dünnen Schnitte oft vorkommt (Fig. 8, Taf. XIII). Da gewahrt man, dass die leicht gewellten Bündel, die nunmehr ihre Kantenansicht darbieten, sich unter sehr spitzen Winkeln vielfaltig gabeln und dann mit den benachbarten Bündeln wieder verschmelzen. Infolge dieser zahlreichen Anastomosen benachbarter Bündel lässt sich jede Lage als ein Pindegewebsplatte mit parallelem Faserverlauf auffassen, die von sehr vielen in Richtung der Fibrillierung ziehenden Schlitzen durchsetzt wird. Gemäss der kreuzschichtigen Faserung benachbarter Lagen wechselt in ihnen die Schlitzrichtung immer um $90^{\circ}$. 
Ein Flachschnitt durch den Teil der Bündelschicht nahe der Epidermis (Fig. 7, Taf. XIII) enthält bei der geringen Dicke der einzelnen Lage gewöhnlich mehrere derselben übereinander, so in unserer Abbildung zwei, deren Faserung rechtwinklig gegeneinander gekreuzt ist. Auch hier finden in jeder Lage zahlreiche Gabelungen und Verschmelzungen benachbarter Bündel statt. Doch nehmen bei der Schmächtigkeit und dem grossen Abstand der Bündel die Spalten mehr Raum ein als diese selbst, und daher tritt der Charakter einer jeden Lage als einer von Schlitzen durchbrochenen Bindegewebsplatte nicht so hervor.

Die geschilderten kreuzschichtigen Lagen werden von schmächtigeren Bündelchen kollagener Fasern, den auch sonst in der Reptilienbant bekanuten "senkrecht aufsteigenden Fasern" durcubrochen, die ihren Weg durch die genannten Schlitze nehmen. Bei schwächerer Vergrösserung erscheinen sie nur als die schon erwähnte, zarte senkrechte Schraffierung längsgetroffenen Lagen (vgl. Fig. 1 und 2, 'Taf. XIII), bei stirkerer erweisen sie sich als ein sehr verwickeltes Flechtwerk, das die kreuzschichtigen Lagen aufs innigste miteinander verbindet. Die senkrecht aufsteigenden Fasern sind (abgesehen von der Nähe der Epidermis; s. u.) parallel den Schlitzen in den gekreuzten Lagen abgeplattet (S, Fig. 8, 'Taf. XIII), und wie deren Richtung von Lage zu Lage wechselt, so ändert sich auch ständig die Ebene der Abtlachung der aufsteigenden Fasern. An der Grenze zweier Lagen der Bündelschicht gehen die benachbarten, senkrecht zueinander abgeflachten Anteile einer aufsteigenden Faser durch eine Zone von kreisförmigem Querschnitt ineinander über. Von diesem eigenartigen Wechsel des Querschnittes der aufsteigenden Fasern kann man sich an genügend dicken Flachenschnitten durch sukzessives Einstellen mit del Mikrometerschraube leicht überzeugen. Infolge dieses Verhaltens der aufsteigenden Fasern (S) werden sie am diagonalen Querschnitt im Niveau der längsgetroffenen Bündel (L) von der Abflachungsebene her, in dem der quer durchschnittenen $(Q)$ in Kantenansicht zu sehen sein (Fig. 4, Taf. XIII).

Die diagonalen Querschnitte lehren aber des weiteren, dass beim jedesmaligen Eintritt in eine neue Lage der Bündelschicht 
eine Umbündelung der aufsteigenden Fasern statthat. Wie Fig. $\bar{y}$ (Taf. XIII) erkennen lässt, bilden sich die aufsteigenden Fasern an der Grenze von Filz- und Bündelschicht durch Zusammentreten mehrerer schmächtiger kollagener Elemente und drängen zunächst durch ihren beträchtlichen Umfang die Bündel der "horizontalen "Lagen auseinander, "wie an den quergetroffeners ohne weiteres festgestellt werden kann. Nach der Epidermis zu werden sie allmäblich so schmächtig, dass unter schwächeren Objektiven die einzelnen quer geschnittenen Bündel sich unmittelbar zu berühren scheinen. Bei hinreichender Vergrösserung (Fig. 4, Taf. XIII) sieht man nun, dass jede Faser (S) beim Übergang aus einer quergetroffenen Bündellage $(Q)$ in die darüber oder darunter gelegene langsgeschnittene (L) sich in zwei (oder mehr) ̈̈ste aufspaltet, die mit denen benachbarter Fasern sich vereinigen und in dieser neuen Anordnung der nächsten Schicht zustreben; hier wiederholt sich der gleiche Vorgang usw. Durch diese Umbündelung erscheint im Niveau der längsgetroffener: Schichten eine zickzackartige Anordnung der aufsteigenden Fasern. Sie ist natürlich in gleicher Weise in der Höhe der quergetroffenen Bündel vorbanden und würde hier auf einem zur gewählten Schnittrichtung senkrechten Durchschnitt zu beobachten sein. Jetzt wird man auch verstehen, dass die bei Flächenbildern sichtbaren Querschnittsgruppen der aufsteigenden Fasern (S) dem Durchschnitt jener zickzackförmigen Anordnung entsprechen (Fig. 8, Taf. XIII).

Gewisse Abweichungen von dem vorstehend geschilderten Bau der Bündellage treten nahe der Epidermis auf (Fig. 3, Tuf. XIII). Es wurde schon erwahnt, dass hier weder die verschiedenen Bündellagen $\left(Q, I_{1}\right)$, noch die Bündel der einzelnen dicht aneinander schliessen, sondern eine allgemeine Auflockerung dieser Schicht stattfindet. Damit făllt, wie für die übrigen kollagenen Bündel; so auch für die senkrecht aufsteigenden Fasern die Ursache der Abpattung fort. Und so begegnen wir dann im Flăchenbild (Fig. 7, Taf. XIII) dieses Niveaus ihren mehr oder minder kreisförmigen Querschnitten. Aber auch die Umbündelung erfolgt hier (vgl. Fig. 3, Taf. XIII) nur spărlich und unregelmässig, und somit verschwindet die Zickzackanordnung der Fasern in der Höhe der längsgetroffenen Lagen. Die senkrecht aufsteigenden Fasern verlaufen in ihrem Endabschnitt leicht geschlängelt zwischen 
den gelockerten horizontalen Bündeln hindurch, gelegentlich sich zu zweien vereinigend, hier und da sich spaltend. Schliesslich setzen sie kegelförmig erweitert an die Epidermis an; die Einzelheiten dieser Verbindung sind im Abschnitt III dargestellt.

Hat man sich an diagonalen Querschnitten und Flächenbildern über den verwickelteñ Bau der Bündelschicht unterrichtet, so kanin man auch aus der Betrachtung orthogonaler Querscbnitte Nutzen ziehen. In solchen (Fig. 10, Taf. XIII) müssen die Bündel sämtlicher Lagen schräg getroffen sein. Das äussert sich an etwas dickeren Schnitten beim Gebrauch der Mikrometerschraube als ein scheinbares einander entlang Verschieben benachbarter Bündellagen nach entgegengesetzten Richtungen; es beruht auf der von Schicht zu Schicht wechselnden Neigung der Faserrichtung zur Miskroskopachse, die beim Ändern der Sehebene als ein Verschieben des optischen Faserquerschnittes zum Ausdruck kommt. Beim orthogonalen Querschnitt gelangen weder Kanten- noch Flächenansichten der aufsteigenden Fasern zur Anschauung; vielmehr werden nur Schrägschnitte der zickzackartigen Faseranordnung sichtbar (S, Fig. 10, Taf. XIII).

Zum Schlusse dieses Abschnittes dürfte es sich empfehlen, noch einmal den gesamten Aufbau der Bündellage an einigen Schemata zu erläutern.

Unter der vereinfachenden Annahme, dass die Bündel der verschiedenen Lagen von gleichem Querschnitt und Abstand sind, sich innerhalb derselben Schicht nicht gabeln und verschmelzen, ferner bei einfachster Gestaltung der Umbündelung der aufsteigenden Fasern und ohne Rücksicht auf ihren Wechsel des Querschnittes lässt sich leicht ein räumliches Schema der $\mathrm{B}$ ündellage geben. In Textfig. B erkennt man obne weiteres die kreuzschichtige Anordnung aufeinander folgender Lagen und kann vor allem rechts die Eigentümlichkeiten des diagonalen Querschnittes (abwechselnd längs- und quergetroffene Bündel, Zickzackanordnung der aufsteigenden Fasern in der Höhe der ersten) feststellen. Besonders klar wird bei genauer Betrachtung des Schemas der Zusammenhang der rechtwinklig gekreuzten zickzackförmigen Anteile der aufsteigenden Fasern in be $\mathrm{nach}$ barten $B$ ündellagen, und man versteht, wie durch diese Anordnung die aufeinanderfolgenden Lagen aufs innigste miteinander verknüpft werden. 


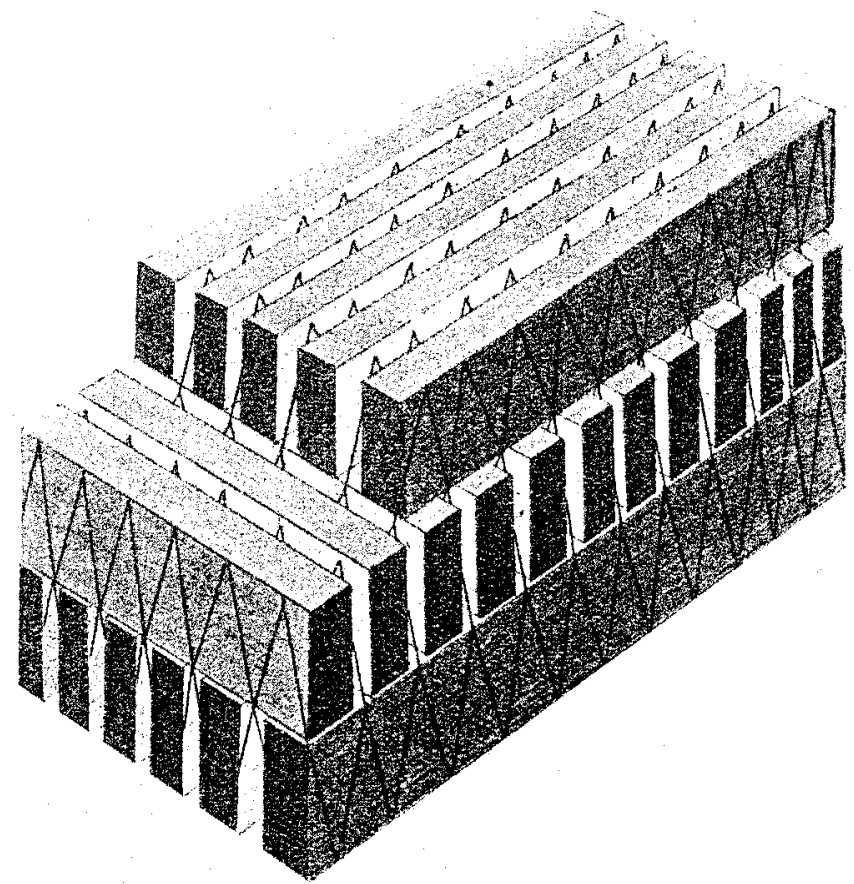

Textfigur $B$.

Vereinfachtes, rüumliches Schema der Bündelschicht.

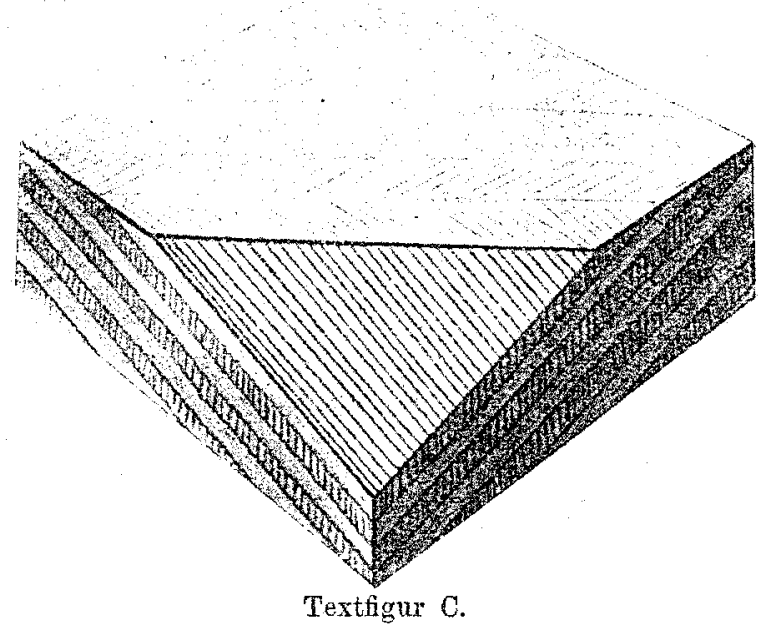

Schema zur Neigung der Bündellagen gegen die Oberfäche der Haut. 
Im Schema $B$ wurde die Neigung der Bündellagen gegen die Oberfläche der Haut ausser acht gelassen. Textfigur $\mathrm{C}^{\circ}$ nimmt darauf Rücksicht; indessen babe jch die Neigung der Schichten stärker genommen als in Wirklichkeit. Auch hier werden die Seiten des quadratischen Stückchens der Bündelschicht von diagonalen Querschnitten begrenzt, die ausser dem Wechsel von quer- und längsgetroffenen Lagen ihr Ansteigen erkennen lassen. An der vorderen oberen Ecke des Stückchens ist eine Partie unter dem Neigungswinkel der Schichtung abgetragen, so dass eine Bündellage freigelegt wird. Auf der oberen Seite sieht man die Bündellagen ausstreichen, wobei infolge ihres wechselnden Faserverlaufes 'eine moiréeartige Zeichnung entsteht, wie sie in der Tat bei Horizontalschnitten durch die Bündellage ähnlich $\mathrm{zu}$ beobachten ist.

\section{b) Filzschicht.}

Nach innen auf die Bündelschicht folgt die Filzschicht (F, Textfig. A, S. 197), die jene an Mächtigkeit bedeutend übertrifft ; misst sie doch bei einem $13,5 \mathrm{~cm}$ langen Exemplar 2,4 mm in der Dicke. Sie besteht aus dicht und anscheinend regellos verwobenen kollagenen Bündeln (F, Fig. 1 und 2, Taf. XIII), die wesentlich schmächtiger sind als jene der Bündellage. Doch lehrt eine aufmerksame Betrachtung, dass eine, wenn auch geringfügige, Bevorzugung gewisser Richtungen für den Verlauf der Bindegewebsfasern besteht, die mit den Beziehungen der Filzschicht zur Bündellage zusammenhängt.

Die Bindegewebsbündel der Filzschicht stellen nämlich einmal die Fortsetzung der aufsteigenden Fasern der Bündelschicht dar. Denn an der Grenze der beiden Hautschichten strahlen die aufsteigenden Bündel kegel- oder pinselförmig auseinander und lassen sich in dieser Form eine ziemliche Strecke weit in die Filzschicht hinein verfolgen (Fig. 1 und 5, Taf. XIII). Andererseits gehen aber auch die horizontalen Lagen der Bündelschicht kontinuierlich in die Filzschicht über. Im vorigen Abschnitt zeigten wir, dass jede derartige Lage gegen die Filzschicht (wie gegen die Epidermis hin) sich verjüngend ausläuft. Betrachtet man das Grenzgebiet von Bündellage und Filzschicht im Fl a ch schnitt der Haut (Fig. 9, 'Taf. XIII), so stellt man fest, dass die einzelnen Fasern einer ausstreichenden Lage 
sich lockern, auseinander weichen, den geordneten Verlauf aufgeben und so allmählich in der Filzschicht sich verlieren.

Somit finden sowohl die horizontalen Lagen, als auch die aufsteigenden Fasern der Bündellage ihre unmittelbare Fortsetzung in der Filzschicht.

Nach innen $\mathrm{zu}$ wird die Filzschicht durch eine fester gefügte Lage von regelmässigerem Faserverlauf abgeschlossen, die sich aber keineswegs gegen die Filzschicht so scharf und bestimmt absetzt wie diese gegen die Bündellage, sondern mehr allmählich aus ihr hervorgeht und als eine periphere verdichtete Zone derselben gelten kann. Hier, in der "Grenzschicht", treten die Bindegewebsfasern wieder $\mathrm{zu}$ dickeren Bündeln zusammen und diese lassen auch eine, wenngleich etwas unregelmässige, Șchichtung erkennen, indem sie auf dem diagonalen Querschnitt überwiegend längs- und quergetroffen erscheinen (Fig. 6, Taf. XIIl). Es findet also auch hier eine kreuzweise Anordnung benachbarter Bündel statt, wobei die Hauptverlaufsrichtungen der Fasern mit jener der Bündelschicht übereinstimmen. Die Dicke der Grenzschicht schwankt zwischen 0,2 und $0,3 \mathrm{~mm}$.

c) Verhalten der verschiedenen Schichten mit Rücksicht auf die Schale als Ganzes.

Im Abschnitt über die Bündelschicht (S. 197) wurde auseinandergesetzt, dass ihre einzelnen Lagen keineswegs der Hautoberflache parallel verlaufen, sondern unter einer gewissen Neigung gegen sie emporsteigen. Die Orientierung dieser Schrägstellung der einzelnen Lamellen ist in bezug a uf die ganze Schale gesetzmässig geregelt, indem die einzelnen Lagen sich so überdecken, dass ihre gegen die Epidermis ansteigenden Abschnitte dem freien Rand der (Bauch- und Rücken-) Schale zugekehrt sind. Ausfuibrlicher gesagt: der Ausgangspunkt jeder Lamelle an der Grenze von Bündel- und Filzschicht liegt der Mitte der Schale näher als ihr der Epidermis zugewandter Endabschnitt; oder, die einzelnen Lamellen decken sich so wie die Schiefertafeln auf einem Dache, d.h. die in bezug auf die Wölbung der Schale höher gelegenen Lamellen überlagern mit ihrem distalen Teil den proximalen der tiefer befindlichen. In Textfigur $D$ ist diese Anordnung der einzelnen Lagen der Bündelschicht auf einem 
diagonalen Schnitt durch die Schale einer $10 \mathrm{~cm}$ grossen Emyda schematisch eingetragen. Der Schnitt geht von vorne rechts (VR) nach hinten links (HL); die knöchernen Bestandteile der Rückenschale sind im ganzen schwarz angelegt, auch die in der Bauchschale getroffenen Ausläufer einiger Plastrallinochen ebenso angedeutet. Die Schrăgstellung der einzeinen Lamellen der Bündelschicht, wie sie aus der Abbildung ersichtlich ist und soeben beschrieben wurde, setzt voraus, dass im mittleren Teil sowohl der Rücken- wie der Bauchschale eine Umkehr dieser Schichtung eintritt; sie lasst sich in der Tat im zentralen Gebiet des Bauchschildes unmittelbar beobachten (vgl. Textfigur D) während in der Rückenschale der Umkehrpunkt in den bereits verknöcherten Teil entfallt.

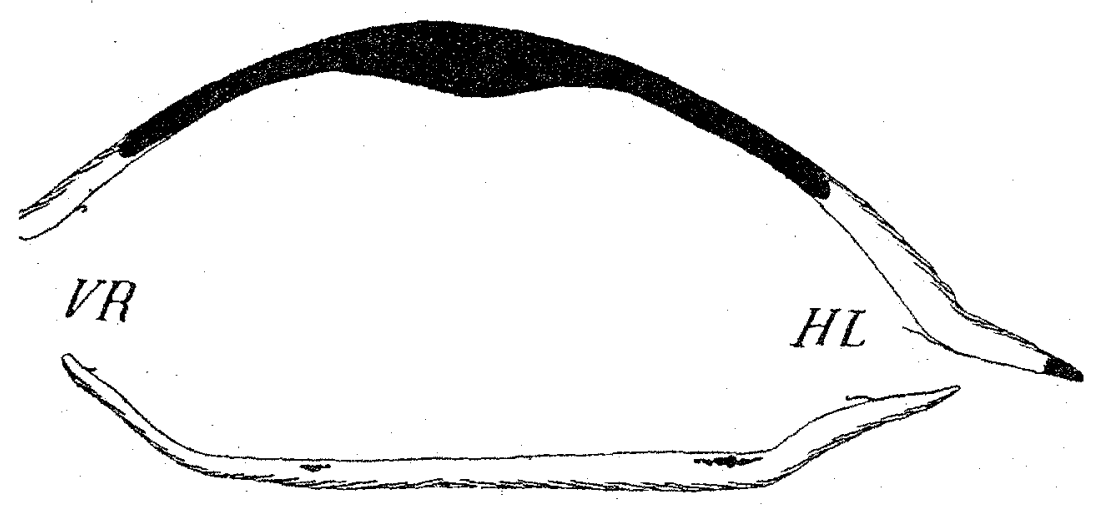

Textfigur $\mathrm{D}$.

Diagonaler Schnitt durch die Schale einer $10 \mathrm{~cm}$ langen Emyda (VR $=$ vorne rechts, $\mathrm{HL}=$ hinten links) zur Demonstration der schrägen Orientierung der einzelnen Lagen der Bündelschieht in bezug auf die ganze Schale.

Das Verhaiten der einzelnen Schichten am freien Rand der Scha le ist überall im wesentlichen gleichartig. Textfigur $\mathrm{E}$ stellt den. freien Rand des Bauchschildes einer $13,5 \mathrm{~cm}$ grossen Emyda auf dem diagonalen Durchschnitt dar. Das abgebildete Stück ist vorn rechts dem Rande des Bauchschildes entnommen and entspricht daher der Lage nach dem aussersten linken Teil der Bauchschale in Textfig. D. Die Bündelschicht (B) nimmt nach dem Schalenrand hin langsam an Stärke ab und Jăuft schliesslich, nur noch aus wenigen Lagen bestehend, ganz 
dünn aus. Die Verjüngung der Schicht erfolgt in der Weise, dass die letzten an der Grenze von Filz- und Bündelschicht beginnenden Lamellen nicht mehr bis in die Gegend der Epidermis vordringen, sondern hinter den nächst voraufgehenden zurückbleiben. Auch die Filzschicht $(F)$ nimmt nach dem Schalenrand hin etwas an Umfang ab und dringt infolge der Verdünnung der Bündelschicht nahe bis zur Oberbaut vor; ihr Unterrand wird von der allmählich sich verjüngenden Grenzschicht (G) begleitet. Der auslaufenden Bündelschicht gegenüber beginnt das gewöhnliche Integument des Körper's (I); einen direkten Übergang der beiden Schichten habe ich nicht feststellen können. Zwischen das gewöhnliche Integument (I) und die Grenzschicht $(G)$ schiebt sich ein sebr lockeres Bindegewebe ein. Ähnlich liegen die Verbältnisse am freien Hinterrand des Bauchschildes und am Rande der Rückenschale. Der Endabschnitt des erstgenannten ist in Textfig. F (entsprechend dem rechten Ende vom Bauchschild in Textfig. D) wiedergegeben. Die Verdünnung der Bündelschicht (B) vollzieht sich in der eben geschilderten Weise; auch die Filzschicht (F) verjüngt sich mitsamt der begleitenden Grenzschicht $(G)$ allmählich zum freien Rande hin. Über die Beziehungen des gewöbnlichen Integuments (I) zur Panzerhaut gilt das vorhin Gesagte. Grenzschicht $(G)$ und Körperhaut $(K)$ sind, solange sie beieinander verlaufen, durch eine lockere Bindegewebsmasse verlnnüpft.

$W_{0}$ an den Seiten des Körpers Rücken- und Bauchschild in unmittelbarem Zusammenhang stehen (Textfig. G), verhält sich die Bündelschicht (B) wie sonst am freien land der Schale, d. h. sie verjüngt sich sowohl am Rücken- (D) wie auch am Bauchschild (V) gegen das Übergangsgebiet bin ganz in der beschriebenen Weise, so dass ein kontinuierlicher Übergang der Bündellage von der Rückenschale zur Bauchschale kaum besteht. Die Filzschicht (F) dagegen nimmt hier nicht an Stärke ab, sondern biegt unverschmälert von der dorsalen zur ventralen Seite des Panzers über. Doch zeigt sie im Übergangsgebiet eine besondere Struktur, indem sie von Fasern durchschossen wird, die von der Grenzschicht $(G)$ ausgehen und sich durchkreuzend zur Bündellage emporsteigen. Der Verlauf dieses Fasersystems lässt sich am einfachsten so erläutern, dass man sich vorstellt, die Grenzschichten von Rücken- und Bauchschale gingen 
an der Übergangsstelle beider gradlinig weiter und spalteten sich dabei jede in einen Fibrillenpinsel auf; indem die beiden Pinsel sich durchkreuzen, kommt die in Textfig. G sichtbare Anordnung der Fasern in der Filzschicht zustande.-

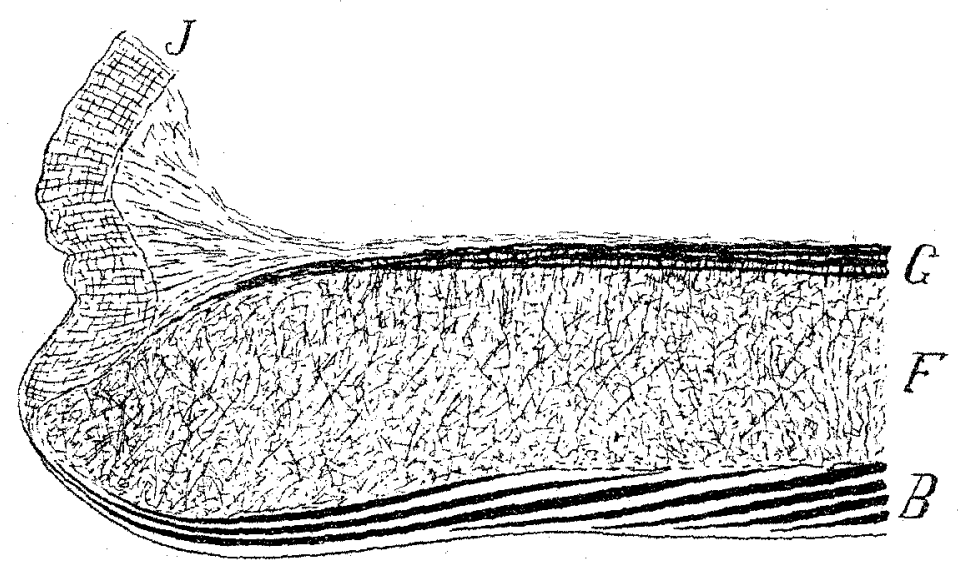

$\mathrm{E}$.

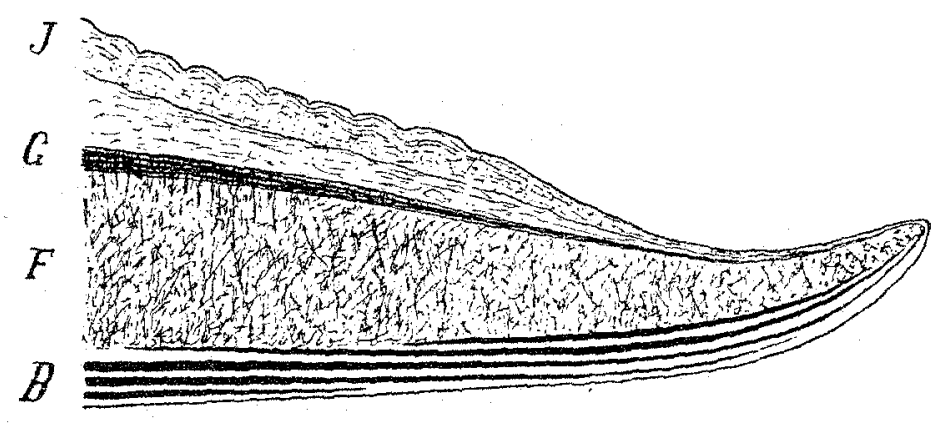

F.

Textfigur E und F.

Freier Rand des Banchsehildes einer $13,5 \mathrm{~cm}$ grossen Enyda auf einem diagonalen Durchschnitt, $E$ rorn rechts, $F$ hinten links (vgl. Textfig. D) Vergr. $7: 1$

Hier sei anch bemerkt, dass gelegentlich die Lamellen der Bündelschicht sich gabeln, bezw. miteinander verschmelzen können; bisweilen tritt dieses Verhalten an ein und derselben Stelle bei allen übereinander geschichteten Lagen ein (vgl. Textfig. $G$ rechts unten). - 
Zum Schlusse dieses Abschnittes noch ein paar Worte über die Bezeichnung der einzelnen bindegewebigen Hautschichten des Panzers.

Während Hoffmann (a. a. o.) es für schwierig erklät, ein allgemeines Bild vom Bau der Haut bei den Schildkröten zu entwerfen und seine Übereinstimmung mit dem der übrigen

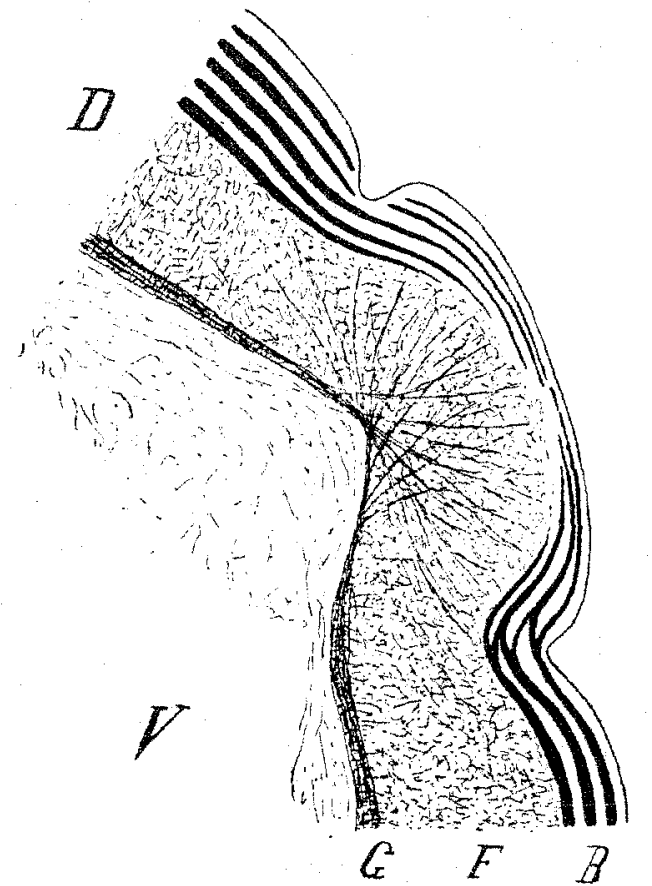

Textfigur $\mathrm{G}$.

Diagonaler Durchschnitt durch den gemeinsamen Seitenteil von Rüchen und Bauchschale einer $13,5 \mathrm{~cm}$ grossen Emyda. $\mathrm{D}=$ Dorsal$\mathrm{V}=$ Ventralseite, $\mathrm{B}=$ Bündel-, $\mathrm{F}=$ Filz-; $\mathrm{G}=$ Grenzschicht. Vergr. $7: 1$.
Reptilien darzutun, äussert Ratbke, der durch den kreuzschichtigen Bau der Lederhaut veranlasst wurde, das Integument verschiedener niederer Wirbeltiere einer Prüfung zu unterziehen, dass die Haut der Chelonier wesentlich den gleichen Aufbau zeige wie bei den anderen Reptilien. Die letztere Anschauung vertritt auch $\mathrm{Ficalbi}$, wenn er eine obere lockere Bindegewebsschicht, eine Lage derber Faserbündel und eine Subkutis unterscheidet, somit den Typus der Lederhaut bei den Schildkröten vorfindet, der nach Leydig allen Reptilien gemeinsam ist (obere lockere Grenzschicht, Grundmasse von festerer Beschaffenheit, untere lockere Grenzschicht). Für eine solche Homologisierung lasst sich weiter noch die Gegenwart der diese Schichten senkrecht durchsetzenden aufsteigenden Fasern verwerten, auf deren Vorkommen zuerst Hoffmann aufmerksam gemacht hat.

Besonderes Interesse verdient nun die Frage, wie sind die 
einzelnen Schichten der Panzerhaut bei Emyda zu deuten. Dass die kreuzschichtige, derbfaserige, von aufsteigenden Fasern durchsetzte Lage dem ähnlich gebauten Teil der Haut des übrigen Körpers entspricht, dürfte keinem $Z$ weifel unterliegen; daher hat auch $\mathrm{K}$ at h ke mit Recht jenen Abschnitt des Panzers als eigentliche Lederhaut bezeichnet.

Anders dagegen verbält es sich mit der Gleichsetzung der Subkutis der Körperhaut und der mächtigen filzartigen Bindegewebsschicht des Panzers, die $R$ at $\mathrm{h} \mathrm{k}$ als Unterbautbindegewebe angesprochen hat. Nach den Untersuchungen von Goette (siehe S. 193) fällt die Rumpfmuskulatur im Bereich des Panzers einer Rückbildung anbeim und tritt selbst in der embryonalen Anlage nur in spärlichen Resten auf. Der von ibr ehemals eingenommene Raum erscheint schon $\mathrm{zu}$ dieser Zeit von einem lockeren Bindegewebe erfüllt, das mit der Anlage der Haut in kontinuierlichem Zusammenhang steht und somit den ganzen Raum zwischen Epidermis und Peritonaeum einbeitlich durchsetzt. Aus dieser Bindegewebsmasse differenziert sich im Laufe der Entwicklung zunächst unter der Epidermis die Kutis (= Bündelschicht bei Emyda); spater nimmt der tiefere Teil den Charakter. von Unterhautbindegewebe an, indem er, wie Goette sich ausdrückt, von der vordringenden Kutis aufgenommen wird; gegen das Peritonaeum hin erhält er einen besonderen, festeren $\mathrm{Ab}$ schluss (Grenzschicht). Wenn man berücksichtigt, dass somit das "Unterhautbindegewebe " im Panzer einen viel grösseren Raum einnimmt (nämlich die Stelle der Muskulatur)'1), als ihm am übrigen Körper zukommt, dass es fermer den Mutterboden für die Hautknochen des Panzers gibt, die bei Emyda dicht über der Grenzschicht entstehen und doch sonst nicht aus der Subkutis hergeleitet werden, und dass schliesslich sein Ba u und seine Aufgabe eine ganz andere ist, als jene des Unterhautbindegewebes im allgemeinen, so erscheint es nicht angängig, diese Schicht einfach dem Unterhautbindegewebe gleichzusetzen. Vielmehr liegt eine Hautschicht--vor, die topographisch, histologisch und funktionell ausgezeichnet ist, nur dem Panzer zukommt und daher einen eigenen Namen beanspruchen kann; nach ihrer Struktur habe ich die Bezeichnung Filzschicht gewählt.

1) Es könnte also in ihm auch peri- und intermuskuläres Bindegewebe vorhanden sein, das beim Schwund der Muskulatur gewuchert ist. 
Man könnte denken, die Frage nach der Homologie der Schichten des Panzers und der Haut im übrigen sei am einfachsten aus dem Verhalten beider an den Übergangsstellen zu lösen. Nach den obigen Erläuterungen (vgl. Textfig. E und F) zeigen Bündelschicht und Korium des gewöbnlichen Körperinteguments keine deutliche Kontinuität, so dass man danach an ihrer doch sonst gut begründeten Homologie zweifeln könnte. Die Filzschicht aber hört sehr gut abgeschlossen auf, steht keinesfalls in unmittelbarem Übergang mit dem lockeren Unterhautbindegewebe; auch dieser Umstand würde also für ihre besondere Natur sprechen.

\section{Der Bau der Oberhaut.}

Die Epidermis des Panzers von Emyda stellt nur einen dünnen (etwa $75 \mu$ starken) Überzug seiner mächtigen bindegewebigen Schichten dar. Wie überall bei den Reptilien besteht sie aus zwei, hier ziemlich scharf gegeneinander abgesetzten Schichten (Fig. 11, Taf. XIV), der äusseren, unter schwachen Vergrösserungen fein horizontal gestreift erscheinenden Hornschicht und der inneren aus zahlreichen Zellagen zusammengesetzten Keimschicht (Stratum Malpighii). Die erste nimmt ungeführ ein Drittel der Gesamtdicke der Oberhaut ein; dass sie im Gegensatze zur Mebrzahl der Schildkröten nur geringe Hürte erreicht, wurde schon in der Einleitung hervorgehoben.

Das Stratum Malpighi i bietet den üblichen Aufbau dar (Fig. 12 Taf., XIV), e i ne Reihe basaler Zylinderzellen und darüber mehrere, nach der Hornschicht zu allmählich sich abflachende Lagen polyedrischer Zellen. Zwei Eigentümlichkeiten springen bei Betrachtung der basalen Zellen sofort in die Augen: ihre Abgrenzung gegen die Lederhaut durch einen breiten dunklen Saum (Fig. 11 11. 12, Taf. XIV), der uns bei Untersuchung der Epidermis-Kutisverbindung näher beschäftigen wird, und der Umstand, dass unter ihren meist ellipsoidalen Kernen in gewissen Abständen und mit ziemlicher Regelmässigkeit viel schlankere und dunkler sich färbende Zellkerne auftauchen (Fig. 11, Taf. XIV). Eisenbämatoxylinpräparate lehren, dass diese fast stäbchenförmigen Kerne entsprechend gestalteten basalen Zellen angehören, die sich sehr stark schwärzen, gewöhnlich etwas verbreitert an dem Unterrand der Epidermis beginnen, sich dann leicht verschmälern und wiederum verbreiternd mit zackig ansgeschnittenen oberen Enden oft 
etwas tiefer wie ihre Nachbarn in die Zone der polyedrischen Elemente einkeilen (Fig. 12, Taf. XIV). Auch auf Flachschnitten der Haut, die durch das Niveau der basalen Zellschicht gehen (Fig. 13, Taf. XIV), erkennt man diese eigenartigen Elemente obne weiteres wieder und gewinnt einen noch besseren Überblick über ihre Verteilung. Hier, quer getroffen, unterscheiden sich diese Zellen nicht nur durch ihre geringere Grösse und stärkere Färbbarkeit von der Ủmgebung, sondern auch durch ihren dreieckigen oder vieleckigen Umriss, von dem scheinbar stellenweise kurze Ausläufer abgehen, die räumlich als flügel- oder lamellenartige Seitenteile des Zelleibes gedeutet werden müssen, die sich zwischen die benachbarten Elemente einschieben.

Prüft man die beschriebenen schlanken, dunklen basalen Epithelzellen an Querschnitten der Epidermis bei hinreichender Vergrösserung, so erweist sich ihre starke Färbbarkeit durch die Anwesenheit kräftig entwickelter Tonofibrillen (Plasmafasern) bedingt (Fig. 26, 'Taf. XIV e, f, g), die in der Längsrichtung der Zelle verlaufen und sich hauptsächlich in ihrer Peripherie halten; was ja schon durch die Lage des Kernes im mittleren Teil der Zelle verständlich wird. Diese Tonofibrillen sind so dicht angeordnet, dass bei kräftiger Färbung mit Eisenhämatoxylin der von ihnen mantelartig umhüllte Kern kaum mehr zu sehen sein kann. Die Querschnitte der Zellen (an Flachschnitten der Haut) zeigen im Plasma zahlreiche dunkle Punkte, die besonders nach dem Rande zu deutlich hervortreten und nichts anderes sind als die quergetroffenen Tonofibrillen (Fig. 14, Taf. XIV). Je nach dem Grade der Diffelenzierung der Eisenhämatoxylinpräparate lassen sich die Tonofibrillen nur in den hier besprochenen schlanken basalen Zellen wahrnehmen (Fig. 14, Taf. XIV), oder sie tauchen auch in der Peripherie del übrigen Zellen mehr oder minder deutlich auf (Fig. 15, Taf. XIV). Somit ergibt sich, dass die uns interessierenden stark färbbaren Elemente keineswegs als eine Zellform eigener Art in der basalen Epidermisschicht gelten können, sondern nur durch eine besonders starke Ausbildung der Tonofibrillen gekennzeichnet sind, wie man denn auch bei einigem Suchen Übergänge in der Form und in dem Verhalten der Plasmafasern zu gewöhnlichen Epithelzellen auffindet. Wir werden später hören, dass diese kräftige Entwicklung der Tonofibrillen durch ihren besonders innigen Zusammenbang mit den aufsteigenden Fasern der Leder- 
haut bestimint wird und daher bezeichne ich diese Zellen schor hier als die Ansatzzellen der anfsteigenden Faseru. Während die früheren Untersucher der Schildkrötenepidermis $Z$ ellbrücken nur mühsam, ungewiss oder gar nicht feststellen konnten, finde ich bei Emyda Interzellularbrïcken im Stratum Malpighii und in der Hornschicht, also in der ganzen Oberhaut, in der schönsten Weise ausgebildet. Zwischen den Seite $n f l a ̈ c h$ en benachbarter Zellen der basalen Epidermisschicht spannen sie sich als zarte Füden aus, die, vor allem leicht am Flachschnitt der Haut sichtbar, die breiten Lücken zwischen benachbarten Zellen (Fig. 14, Taf. XIV) überbrücken, indem sie sich jederseits an einen der dunklen Punkte ansetzen, die wir eben als Querschnittsbilder der Tonofibrillen kennen lernten (Fig. 1 5 , Tafel XIV). An der oberen Fläche der basalen Epidermiszellen erscheinen sie ihnlich in fadenförmiger Gestalt (Fig. 25, Taf. XIV). In der übrigen Oberbant dagegen sind die Interzellularlücken gewöhnlich schmäler, daher auch die Brücken kürzer, dabei stark fürbbar, so dass sie meist als dicht gedrangte Punlite die Zellen umrahmen (Fig. 12, Taf. XIV). Vor allem schön lässt sich ihr Verhalten an Flachschnitten der Haut studieren. Stellt man auf den mittleren. kernbaltigen 'Teil einer der polyedrischen Zellen des Stratu m Malpig hi i ein, so erscheint ihr Rand dicht von dunklen Punkten, den kornartigen Brücken, besetzt (Fig. 17, Taf. XIT). Hebt man nun den Tubus langsam, so treten anf der jetzt sichtbar werdenden Oberfläche der Zelle zahlreiche, dicht gedrängte Punkte von gleicher Grösse hervor, deren kontinuierlicher Übergang in die erstgenannten bei Betătigung der Mikrometerschraube festzustellen ist; sie bieten die Zellbrücken in der Flächenansicht dar. In Fig. 19 (Taf. XIV) sind drei benachbarte Zellen wiedergegeben, davon eine in Aufsicht auf die Zelloberfläche, die beiden anderen im optischen Schnitt.

Auch in der Hornschicht bleiben die Zellbrücken nnverändert deutlich und lassen sich bis in ihre äussersten Lagen hinein verfolgen, ja sind noch auf der freien Aussenfläche der Hornschicht als feine kurze Erhebungen im Querschnitt wahrnehmbar (Fig. 22, Taf. XIV). Die Elemente der Hornschicht platten sich nach aussen zu ständig ab und werden so schliesslich \%u ganz dünnen Schüppchen, die bei schwächeren Vergrösserungen insgesamt der Hornlage die feine Horizontalstreifung verleihen 
(Fig. 11, Taf. XIV). Wenn nun auch mit fortschreitender Abflachung die In terzellular lü cken schmäler werden, so verschwinden sie doch nie ganz. Die Zellbrücken, welche im Stratum Malpighii gelegentlich noch fadig sein können (Fig. 22, Taf. XIV, untere Zellagen), wobei eine knotenartige Verdickung in der Mitte des Fadens (Bizzozerosche Knötchen, Mittelknötchen) bemerkbar wird, zeigen in der Hornschicht durchweg die gedrungenere Form von Körnern. Wie in den tieferen Schichten der Haut, so vermitteln also bei Emyda a uch in der. Hornlage die Zellbrücken den Zusammenhang der einzelnen Elemente, ein Verhalten, das meines Wissens in keinem Falle mit solcher Deutlichkeit nachgewiesen werden konnte.

Von den Ton ofibrillen der basalen Zylinderzellen wurde bereits mitgeteilt, dass sie in der Längsrichtung dieser Elemente verlaufen. Selbst an ungefärbten Präparaten lassen sie sich hier als zarte Streifung der Zellen andeutungsweise erkennen. Auch im übrigen $\mathrm{Stratum} \mathrm{Malpighii,} \mathrm{in} \mathrm{dem} \mathrm{diese} \mathrm{faserigen}$ Bildungen durch Vermittlung der Zelibrücken aus einer Lage in die andere übergehen, ist die allgemeine $Z$ ugrichtung der Plasmafasern senkrecht zur Oberfläche der Epidermis. Die Fibrillen sind hier aber gewöhnlich sehr viel schwächer ausgebildet und erscheinen vielfach nur als eine faserige Beschaffenheit des Zellplasmas im allgemeinen. Wenn man an Flachschnitten der Haut auf den optischen Durchschnitt der polyedriscben Zellen einstellt, so gewahrt man eine allerdings viel undeutlichere Punktierung wie auf ibrer Oberflache (Fig. 17, Taf. XIV): das ist das Querschnittsbild der Tonofibrillen. Hier und da treten einzelne Fibrillen als dunklere Punkte aus der Masse der übrigen hervor, so insbesondere im Umkreis des Zellkernes.

Ein vorzügliches Objekt, um den Verlauf der Tonofibrillen in der gésamten Epidermis zu studieren, ist die $\mathrm{Oberhaut}$ der Lippenanhänge von Emyda, auf die deshalb noch etwas genauer eingegangen werden soll. Im Stratum Malpighii sind die Interzellularlücken sehr weit und von dünnfädigen Brücken durchsetzt, in deren Mitte eine starke, knötchenartige Verdickung eingeschaltet ist (Fig. 16, Taf. XIV). Der fădige Abschnitt der Brücken erstreckt sich jederseits als zarte Fibrille im Plasma der angrenzenden Zellen fort, wobei im allgemeinen eine Verlaufsrichtung der gesamten Faserung senkrecht zur Fläche der Epi- 
dermis zustande kommt. An manchen Stellen machen sich einzelne Faserzüge durch dickere Ausbildung und stärkere Färbung der Fibrillen bemerkbar und lassen sich so durch eine Anzahl übereinander gelegener Zellen mühelos hindurch verfolgen (Fig. 16: Taf. XIV). Dabei stellt man fest, dass die in diesen kraftigeren Zügen von Tonofibrillen gelegenen Mittelknötchen der Brücken durch bedeutendere Grösse ausgezeichnet sind. Solche Züge von Plasmafasern zeigen auch nicht selten Gabelungen (Fig. 16, Taf. XIV, unterste Zelle).

Geht man in der Lippenhaut dem Verhalten der Tonofibrillen gegen die Hornschicht zu weiter nach, so ergibt sich, dass sie auch in den verhornenden Zellen, im Grenzgebiet zwischen Keim. und Hornschicht, erhaiten sind; nur ist ihre Verlaufsrichtung vollkommen geăndert. Jede platte Zelle der genannten Zone erweist sich auf dünnen Querschnitten aus zablreichen, dicht gelagerten, in der Abflachungsebene verlaufenden Fasern zusammengesetzt, deren Beziehung zu den Zellbrücken stellenweise einwandfrei $\mathrm{zu}$ erkennen ist (Fig. 21, Taf. XIV). Ich stehe nicht an, in dieser Umordnung der Fibrillen das unmittelbare Ergebnis der Formänderung der polyedrischen Zelle zu einem abgeplatteten Schüppchen zu erblicken. Betrachtet man eine solche Zelle von der Flăche, so sieht man die Tonofibrillen grösstenteils als unregelmässig gewellte, dicke, offenbar stellenweise aus mehreren Fäden verklebte Elemente den Kern allseits umziehen (Fig. 23, Taf. XIV). In der năheren Umgebung des Zellkernes, also dort, wo das Schüppchen am dicksten ist, findet man eine undeutliche Punktierung (Fig. 23, Taf. XIV), die Querschnitten von Tonofibrillen entspricht, also Verhältnisse, die noch mehr an die Zustände der polyedrischen Zellen (vgl. Fig. 17, Taf. XIV) erinnern. In den vollkommen verhornten Zellen konnte ich keine Tonofibrillen mehr unterscheiden.- Doch nehme ich an, dass sie auch hier erhalten und nur infolge der überaus starken Abplattung der Zellen so dicht aufeinandergepresst sind, dass sich einzelne nicht mehr optisch und färberisch isolieren lassen. Ganz verbornte Zellen bieten bei Flächenbetrachtung nur die dichte und kräftige Punktierung ihrer Obertlache dar, die durch die Anwesenheit der Interzellularbrücken bedingt ist (Fig. 24, Taf. XIV).

Überschauen wir nochmals den Gesamtverlauf der Tonofibrillen in der Epidermis, so ergibt sich, dass sie 
im Stratum Malpighii überwiegend senkrecht zur Oberflache der Epidermis gerichtet sind, in der Hornschicht dagegen dieser parallel ziehen. Dieses allgemeine Frgebnis stebt durchaus in Übereinklang mit den bei anderen Objekten, insbesondere der menschlichen Epidermis, gewonnenen Befunden. ${ }^{1}$ )

Ficalbi (s. o.) hat bei Schildkröten auf das Vorhandensein eines Stratum granulosum in der Epidermis kurz.hingewiesen. Bei meinem Objekt, Emyda granosa, habe ich lange vergebens nach Keratohyalin in der Epidermis geforscht; an Querschnitten der Haut war nichts Sicheres davon zu erblicken. Schliesslich stiess ich aber auf Flachschnitten an der Grenze von Horn- und Keimschicht auf Zellen, die in ihrem Plasma eine Gruppe seitlich vom Kern gelegener kleiner rundlicher Körnchen von wechselnder Grösse enthielten, welche sich mit Eisenbämatoxylin stark färbten (Fig. 20, Taf. XIV). Hier haben wir also eine sehr spärliche Keratohyalinentwicklung vor uns.

Der Verhornungsprozess bei Emyda ist, verglichen mit der Schildpattbildung anderer Chelonier, recht kümmerlich. Während bei den Reptilien im allgemeinen die in Verhornung eintretenden Zellen eine dicke exoplasmatische Rinde als hauptsãchlichen Sitz der Keratinisation von einem längere Zeit unverăndert bleibenden, den Kern umschliessenden Endoplasma unterscheiden lassen, konnte ich bei Emyda von dieser Differenzjerung nichts wahrnehmen. Auch die von Ficalbi (s. S. 193) bei verschiedenen Schildkröten festgestellte Gliederung der Hornschicht, die das Schildpatt als mehrere nicht abgeworfene Epidermisgenerationen (der Art, wie sie bei Eidechsen und Schlangen in jeder Hăutung entfernt werden) aufzufassen nötigt, fehlt bei Emyda durchaus: hier ist die Hornschicht eine ganz einheitliche Lage. Eine besonders differenzierte Zellschicht auf der Aussenseite der Hornschicht (Oberhautchen) fehlt wie bei allen Schildkröten, was bei dem Mangel richtiger Hăutungen nicht verwunderlich ist.

In der Epidermis der Rückenschale beherbergt das Stratum Malpighii verăstelte Pigmentzellen (M e la nophoren), der Bauchschale fehlen sie vollkommen. Von diesen Elementen wird offen-

i) Über das Verhalten der Epidermistonofibrillen bei Emyda vgl. auch meine im Aroh. f. Zellforschung Bd. XVI erscheinende Abhandlung: Über den Nachweis der Epidermis-Tonofibrillen bei Emyda im polarisierten Licht. 
bar Pigment an gewöhnliche Epidermiszellen abgegeben. Bisweilen gelangen sie beim Wachstum der Epidermis in die Hornschicht hinein und geben hier zugrunde.

Gelegentlich stösst man auf $\mathrm{z}$ weikernige $Z$ ellen in der Epidermis (Fig. 18, Taf. XIV), ferner auf Elemente, die ausser dem Kern einen bläschen förmigen Einschluss ( 4 « und kleiner) mit kräftig färbbarer Wandung besitzen (Fig. 17, Taf. XIV); seine Bedeutung und Herkunft vermag ich nicht zu erklären.

\section{Die Epidermis-Kutisverbindung.}

Der unterste Abschnitt der basalen Epidermiszellen fällt (selbst am ungefärbten Präparat) als eine bandartige Zone auf (Fig. 11 u. 12, Taf. XIV), die stark Kollag en s t of f e (z. B. Säurefuchsin) speichert. Unter schwächeren Vergrösserungen zeigt sie eine Art Querstreifung oder Zusammensetzung aus kleinen, senkrecht zur Epidermis gestellten Stäbchen. Diese erwiesen sich unter starken Objektiven als. Fortsetzung der a ufsteigenden Fasern: jede derselben zerfällt nämlich, in der Năhe der Epidernis angelangt, in eine Anzahl von kollagenen Fasern, die etwas auseinanderweichen und damit insgesamt die Form eines schianken Kegels annehmen (Fig. 25, Taf. XIV). Die mittleren Fasern eines solchen Endkegels streben auf geradem Wege der Epidermis $\mathrm{zu}$, die peripheren dagegen biegen zunächst allseits ab, so dass sie sich mit denen benachbarter aufsteigender Fasern guirlandenartig treffen. Schliesslich aber dringen beiderlei "Fasern “ - wie es zunächst den Anschein hat - in die Epidermis ein und zwar nicht nur in die Interzellularlücken $z$ wischen den basilen Zylinderzellen, sondern in diese Zellen selbst. Dieser letzte in die Epidermis vordringende Teil der aufsteigenden Bündel verursacht die schon bei schwächeren Vergrösserungen wahrnehmbare kollagene Zone der Epidermis.

In bezug auf die Einzelheiten dieser Endigung der aufsteigenden Fasern, wie sie am Querschnitt der Haut erscheint, ist noch folgendes bemerkenswert. Vielfach tritt am Unterrand der Epidermis eine Verschmälerung der einzelnen kollagenen „Fasern" auf, die aber weiterhin sich wieder verdicken und so das Ansehen ganz schlanker Keulchen gewinnen (Fig. 25, Taf. XIV), die alle in der gleichen Höhe der Oberhaut ihr Ende erreichen. Aus dem letzteren Grunde ist die kollagene Zone der Epidermis 
fast geradlinig begrenzt. Auf jede Epidermiszelle entfallen zwei bis vier der geschilderten "Fasern". An dünnen Schnitten und bei hohen Vergrösserungen sieht man aber, dass auch die unteren, $\mathrm{z}$ wischen den Fasern gelegenen Enden der basalen Epidermiszellen, dre etwa $1 / 4$ ihrer Länge ausmachen, eine vom übrigen Teil der Zelle abweichende kollagene Färbung besitzen (in Fig. 25, Taf. XIV nur leicht angedeutet) und zwar erscheinen sie bei Tinktion mit (Eisenhämatoxylin und) Pikrin-Säurefuchsin nach van Gi i s on zart rötlich gegenüber dem gelben Rest der Zelle. Die obere Grenze der rötlichen Farbe geht genau so weit, wie die eindringenden Fasern. Was sie zu bedeuten hat, ergibt sich aus Flachschnitten.

An Horizontalschnitten durch die Epidermis begegnet man nämlich in dem Niveau des unteren Abschnittes der basalen Zylinderzellen einem Netzwerk aus kollagener Substanz, das polygonale, drei- bis sechseckigè Maschen besitzt, deren Grösse etwa zwischen 2 und $4 \mu$ schwankt (Fig. 27, Taf. XIV). Die Balken des Netzes sind nicht von gleicher Dicke, im allgemeinen messen sie etwa 1 . . Bei Betrachtung eines grösseren Abschnittes dieses Netzes treten in ihm einzelne stärkere Züge hervor, die sich über eine Anzahl Maschen hinweg verfolgen lassen (Fig. 27 und 28, Taf. XIV). Hier und da sieht man in einzelnen Maschen kleine, blind endigende $Z$ weige des Netzwerkes eine kurze Strecke weit einspringen.

Setzen wir diese Beobachtung mit der erstgenannten am Querschnitt der Haut in Znsammenhang, so ergibt sich, dass die in der Epidermis gelegenen Endabschnitte der aufsteigenden Fasern nicht fadenförmig sind, wie es zuerst scheinen möchte; sondern als die (reellen und optischen) Querschnitte der Netzmaschen gelten müssen. Damit findet auch die abweichende (kollagene) Färbung des unteren Endes der basalen Epidermiszellen ihre Erklärung. Sie wird durch jene Abschnitte der Netzbalken bedingt, die im Querschnitt der Haut von der Fläche aus sichtbar sind.

Dass diese Verknüpfung von Quer- und Flachschnittbild richtig ist, folgt mit zwingender Notwendigkeit aus einer Kontrolle der Beziehungen zwischen dem basiepithelialen Netz, wie ich es im folgenden nennen will, und den a ufsteigenden Fasern an Flachschnitten. Da die Horizontalschnitte der Haut selten genau der Oberfăche parallel gehen, schon deshalb, weil 
diese auf grössere Ausdehnung hin nie vollkommen eben ist, lassen sich an ein und demselben Schnitt häufig in dem gleichen Gesichtsfeld des Mikroskops die Bilder benachbarter Niveaus miteinander vergleichen. Schreitet man so allmäblich von der Epidermis zur Lederhaut fort, so gewahrt man zunachst, dass die Maschen des basiepithelialen Netzes kleiner und rundiicher, die sie begrenzenden Züge dagegen dicker werden (Fig. 29, Taf. XIV). Ist man am Unterrand der Fpidermis angelangt, so hat sich das Verhältnis ron Maschen und Balken des Netzes geradezu umgekehrt: der Durchmesser der Maschen ist kleiner als die Dicke der sie umschliessenden Netzbalken, so dass der Eindruck eines Netzes fast verloren geht und an seine Stelle das Bild einer Platte getreten ist, die von zahlreichen, zu Gruppen geordneten, relativ kleinen Öffnungen durchbrochen ist (Fig. 30, Taf. XIV). Weiter in die Lederhaut hinein zerfällt das Netz in einzelne iundliche Abschnitte, die nichts anderes sind als die liegelförmig ausgeweiteten Enden der anfsteigenden Fasern; nunmehr bilden die Öffnungen nur noch zerstreute kleine, fast punktförmige Gebilde ${ }^{1}$ ) (Fig. 31, 'Taf. XIY'). Schliesslich verschwinden anch diese; der Quersehnitt der anfsteigenden Fasern verjüngt sich; anfangs besitzt el vor allem im mittleren Teil noch eine lockere Beschafienheit, so dass er wiederum netzartig erscheint (Fig. 32, Taf. XIV); bald aber nimmt er, zunïcbst in der Peripherie dichtes Gefüge an. Die hier geschilderten Bilder lassen sich an $15 \mu$ dicken Sehnitten durch schrittweises Einstellen auf verschiedenen Ebenen an ein und demselben Querschnitt einer aufsteigenden Faser verfolgen.

Die Gesamtbeit unserer Beobachtungen lehrt also, dass die aufsteigenden Fasern, an der Unterseite der Epidermis angelangrt, sich aufsplittern, zum basiepithelialen Netz vereinigen und in das Epithel eintreten. Man kam somit sagen, dass das Netz a us den a ufsteigenden Fasern hervorgeht. Doch hängt es auch mit den Lagen der $B$ ündelschicht innig zusammen. Wie früher beschrieben, steigen diese Lagen, immer schmachtiger werdend und unter Lockerung der einzelnen Bündel voneinander; unter schrägem Verlauf bis dicht an den Unterrand der Epidermis heran. Auf senkrechten Durchschnitten der Haut ist über die Art der Endigung der einzelnen Bündel nichts Gewisses zu erkennen. An Flachschnitten dagegen kamn man wenigstens fest-

\footnotetext{
1) Sie sind an der Anwesenheit der Tonotibrillen kenntlich (s. S. 200).
} 
stellen, dass hier und da ein einzelnes Bündel in das basiepitheliale Netz eintritt (Fig. 28, Taf. XIV): ohne seine allgemeine Verlaufsrichtung zu ändern, gibt es mehrfach Seitenzweige an das Netz ab und löst sich so schliesslich ganz in ihm auf. Ich möchte vermuten, dass die oben erwähnten stärkeren Züge im basiepithelialen Netz grossenteils auf seinen Zusammenhang mit den horizontalen Bündeln zurückzuführen sind. Entsprechend dem gekreuzten Verlauf benachbarter Lagen der Bündelschicht treten ihre Fasern in zwei zueinander senkrechten Richtungen an das basiepitheliale Netz heran.

Das basiepitheliale Netz ist am schönsten darstellbar durch mässig starke Fảrbung mit Eisenhämatoxylin und kräftige mit Pikrinsäure-Săurefuchsin nach van Gi es on. Auch bei der Doppelfärbung Eisenhämatoxylin-Eosin tritt es klar hervor; selbst bei einfacher Färbung mit Eisenhämatoxylin lässt es sich durch entsprechende Differenzierung wohl kenntlich machen.

Wie verhalten sich nun die Epidermiszellen zu dem basiepitbelialen Netz? Aus dem Querschnitt der Haut (Fig. 25, Taf. XIV) ergab sich, dass in jede basale Epidermiszelle $z w e i$ bis vier der scheinbar faserartigen Endauslaufer der aufsteigenden Fasern eintreten. Damit steht in Übereinklang, dass im Flachschnitt auf je eine basale Epidermiszelle mehrere Maschen des basiepithelialen Netzes entfallen; man vergleiche z. B. die bei derselben Vergrösserung wiedergegebenen Fig. 14 u. $15 \mathrm{mit}$ Fig. 29 u. 30 (Taf. XIV). Das untere Ende jeder basalen Zylinderzelle ist also in mehrere Fortsatze ausgezogen, deren jeder in einer Masche des Netzes rubt. Die Gestalt der Fortsätze muss natürlich der Form der Maschen entsprechen, da sie jene ausfüllen; man wird sie als ungefähr zitzenförmig bezeichnen können, da nach dem vorhin Gesagten die Netzlücken gegen die Kutis hin allmählich kleiner werden. Das gilt besonders für die Zellen, welche mitten ïber einer aufsteigenden Faser gelegen sind und tief in ibren Endkegel hineinragen (vgl. Fig. 25, Taf. XIV). Jetzt verstehen wir auch die Gruppierung der Netzmaschen, die bei Flachschnitten ganz nahe der Kutisgrenze sichtbar ist (Fig. 29 u. 30, Taf. XIV): jede Gruppe umfasst die Gesamtheit der Ausläufer einer einzelnen Epidermiszelle.

An stark mit Eisenhämatoxylin gefärbten Präparaten ist 
jede Masche des basiepithelialen Netzes von einem Kranz dunkler Punkte eingesäumt (Fig. 29 u. 30, Taf. XIV), und gerade diese Eigentümlichkeit lässt schon bei alleiniger Tinktion mit dem genannten Farbstoff die Netzlücken scharf hervortreten und gestattet, sie bis $\mathrm{zu}$ den geringsten Dimensionen hinab zu verfolgen. Die Punkte sind nichts anderes als $Q$ uerschnit te von Ton ofibrillen, die somit nicht nur als einheitlicher Mantel den oberen (kernhaltigen) 'Teil der basalen Epidermiszellen umbüllen, sondern auch in die Fortsätze eintreten und sich hier so anordnen, dass sie wiederum ganz ausgesprochen sich in der Peripherie jedes Fortsatzes halten. In dem Maße, wie die Fortsätze sich zur Kutis hin verschmälern, drängen sich die Fibrillen in ihnen zusammen, so dass die Fortsätze zuletzt nur noch ein Bündel von Tonofibrillen darstellen (Fig. 31, Taf. XIV).

Die Beziehungen zwischen den Tonofibrillen und dem basiepithelialen Netz sind auf Querschnitten der Haut schwierig zu deuten. Nur die optischen Durchschnitte der Netzmaschen sind deutlich wahrzunehmen und erscheinen unter dem Trugbild von Fibrillen (Fig. 25, Taf. XIV); doch kam man sich auch hier durch sorgsame Handhabung der Mikrometerschraube überzeugen, dass diese „Fibrillen" nicht faden-, sondern lamellenartig sind. Dass dagegen die zarte kollagene Fürbung des unteren Saumes der Epidermis durch die Hachenhaft sichtbaren Anteile der Netzmaschen hervorgerufen werden lässt sich höchstens an gelockerten Stellen der Schnitte feststellen (Fig. 26 a und b, Taf. XIV): hier gewinnt man den Eindruck, dass die an die Zellen herantretenden Fasern sich flächenhaft verbreitern und ibnen anlegen.

Fasst man zunächst die erwähnten fibrillenartig erscheinenden Kantenansichten der Netzmaschen ins Auge, so gewabrt man oft, dass die Tonofibrillen, weiche die basalen Zellen mantelartig umhüllen, am oberen Rande des basiepithelialen Netzes endigen und zwar so, dass jede Tonofibrille in einer kollagenen "Faser" ihre Fortsetzung findet (Fig. 26 c, Taf. XIV). Bei einem solchen Verhalten würden also die Fortsätze der basalen Zellen, die in die Netzmaschen hineinragen, ohne Tonofibrillen sein. Diese Auffassung widerspricht aber dem Flachschnittbild, in dem jede Netzmasche von den punktförmigen Durchschnitten der Tonofibrillen umsäumt ist. Und in der Tat lässt sich oft bei genauer Beobachtung feststellen, dass die Tonofibrillen, an der kollagenen 
Faser angelangt, sich gabeln und sie beiderseits weiter begleiten (Fig. 26 c, Taf. XIV). Was so als Gabelung einer Tonofibrille erscheint, mag in vielen Fällen derart zustande kommen, dass $z$ wei bis dahin dicht beieinander ziehende Tonofibrillen, am basiepithelialen Netz angelangt, auseinanderweichen und in benachbarte Netzmaschen eintreten. Übrigens will ich keineswegs bestreiten, dass auch tatsächlich an der Obergrenze des basiepithelialen Netzes Tonofibrillen endigen; dafür sprechen vor allem jene seltenen Fälle, in denen ich den Zusammenbang eines flächenhaft getroffenen Netzbalkens mit den Tonofibrillen wahrnehmen konnte (Fig. 16 d, Taf. XIV). Die Regel stellt ein solches Verhalten aber nicht dar; vielmehr lässt sich vor allem an den schlanken, tief geschwärzten basalen Zellen mit Sicherheit erkennen, dass die Tonofibrillen in die basalen Fortsaitze der Zellen eintreten, indem sie $\mathrm{zu}$ einem Büschel auseinanderfahren (Fig. 26 e-g, Taf. XIV). Eine derartige Endigung der Tonofibrillen muss ja auch nach den schon besprochenen Flachschnittbildern ohne weiteres erwartet werden.

Hier ist der Ort, auf die Lagebeziehungen zwischen den scblanken Zellen mit kraftiger Ausbildung der Tonofibrillen und den a usteigenden Fasern des Koriums hinzuweisen. Diese Zellen befinden sich stets mitten über dem Ansatz einer aufsteigenden Faser, d. h. sie hängen mit jenen Maschen des basiepithelialen Netzes zusammen, die aus dem zentralen Teil einer aufsteigenden Faser hervorgehen, der geradewegs zur Epidermis emporstrebt. Daher habe ich sie schon oben als die Ansatzzellen der aufsteigenden Fasern bezeichnet. Bei der Untersuchung von Querschnitten der Haut (Fig. 11 u. 12, Taf. XIV) muss man mit Rücksicht auf diesen Zusammenhang in Betracht ziehen, dass er auf dünnen Schnitten nicht immer zum Ausdruck kommen kann, weil die aufsteigenden Fasern oft nicht ganz gerade und senkrecht zur Epidermis verlaufen; daher wird man hier und da tief geschwärzte Zellen finden, unter denen keine aufsteigende Faser sichtbar ist, und umgekehrt aufsteigenden Fasern begegnen, die einer Fortsetzung durch fibrillenreiche basale Zellen zu ermangeln scheinen.

Zum Schlusse dieses Abschnittes ein paar Hinweise über die in der Literatur vorliegenden Angaben betr. Epidermis Kutisverbindung bei den Reptilien! Krauss (1905) hat 
diese Frage zum Gegenstand einer besonderen Untersuchung gemacht und ist $z$ u dem Ergebnis gekommen, dass in einer bestimmten Periode der Embryonalentwicklung die Entstehung der Kutis vom Rete Malpighii ausgebt, und dass solche an die Embryonalentwicklung erinnernde Verhältnisse auch in der Haut mancher erwachsener Reptilien vorkommen, sei es in der Form protoplasmatischer oder gallertgewebeartiger Partien zwischen Elidermis und Kutis oder einer mangelhaften kollagenen Abgrenzung der Epidermis von der Kutis. So sieht denn auch $\mathrm{Krauss}$ in den Verzahnungen der Kutis mit der Epidermis eine "Kollagenbildung im basalen Protoplasmagebiet der Epidermiszellen". Schon vor Jahren (W. J. Sclu mid t 1910, S. 689 u. 1913 S.399) habe ich micht dahin geäussert, dass mir bei meinen vielfältigen Untersuchungen am Integument der Reptilien niemals etwas vor Augen gekommen. ist, das diese Anschauungen von Krauss stüten könnte, indem ich weder in embryonaler Zeit noch beim erwachsenen Tier Übergänge zwischen dem Plasma del basalen Epidermiszellen und der kollagenen Substanz feststellen konnte. Wenn ich somit grundsätzlich einen anderen Standpunlit als der genannte Autor einnehme, so finden sich doch bei ihm viele richtige Beobachtungen.

Unter den verschiedenen Arten der Verbindung von Elidermis und Kutis erwähnt Krauss die Verzahnung beider Schichten, wie er sie vor allem beim Alligator beobachten konnte. Sie beruht darauf, dass die an die Epidermis angrenzenden kollagenen Fasern kleine Zahne in und zwischen die Protoplasmakörper der basalen Epithelzellen hineinsenden. T)as Bild, welches Kr a us zur Illustration dieser Verbindung gibt (Fig. 14, Taf. 23 a. a. 0.), entspricht durchaus unserer Figur 25 (Taf. XIV), hinsichtlich des Verbaitens der in die Epidermis eindringenden kollagenen "Fasern". Nu fasst Krauss die eindringenden kollagenen Massen beim Alligator als wirkliche Fasern auf, während wir bei Emyda in ihnen die optischen und reellen Durchschnitte des basiepithelialen Netzes erkannten.

Nun hat abel schon L, woff (1885) in der Hant junger Krokodile beobachtet, dass die untere Grenze der Epidermis zahnartig ausgeschnitten ist und ahnliche Zahnchen auch auf der oberen Fläche der Kutis $z u$ sehen sind. "Der erste Eindruck" von diesen Prïparaten führt zu dem Schlusse, dass die 7abuchen 
der Epidermis und der Kutis in der normalen Lage die Vertiefungen zwischen einander einnehmen und also die Verbindung $z$ wischen diesen zwei Schichten der Haut befördern “ (S. 320-321 a. a. 0.). Um die Art dieser Verbindung genauer festzustellen, untersuchte Lw off die Zähnchen der Epidermis und Kutis en face: an solchen Präparaten stellte die Oberfläche der Kutis ein Netzwerk von dünnen Querbalken dar, die kleine, bald rundiche, bald langliche $Z$ wischenräume $n$ mschliessen; das Netzwerk erhebt sich leistenartig über die Oberfläche der Kutis. Vergleicht man Fig. 6 (Taf. VI) bei L w off mit unseren Abbildungen Fig. 27 und 29 (Taf. XIV), so ergibt sich mit Sicherheit, dass der Autor das basiepitheliale Netz vor Augen gehabt hat. Die Unterseite der Epidermis bot $L w$ off ein ahnliches Bild von einem Netzwerk dar, und zwar entfielen auf die Unterfiäche jeder Zelle 10-12 Netzmaschen, wie mit einer hübschen Abbildung (Fig. 7, Taf. VI a. a. O.) belegt wird. So kommt denn Lw off zum Schluss, dass von der unteren Fläche der Epidermis, ebenso von der oberen der Kutis, Leisten oder Brïcken einander entgegengehen, die an Querschnitten als Zähnchen erscheinen.

Krauss (1905), dem Lw of fs Arbeit bekannt ist, geht auf die vorstehend mitgeteilten Beobachtungen dieses Autors nicht näher ein, anscheinend, weil er selbst keine Flächenbilder untersucht hat und daher mit der $\mathrm{L}$ w of fschen Darstellung nichts anzufangen wusste. Bei Emyda finde ich die Angaben des russischen Forschers durchaus bestatigt und daher glanbe jch auch, dass sie fürs Krokodil zu Recht bestehen; ja ich möchte vermuten, dass ein basiepitheliales Netz vielfach dort ausgebildet ist, wo man bisher von einer Verzahnung durch fadenartige kollagene Elemente gesprochen hat.

Nach Krauss (a. a. O.S. 344 und 356 ) geben die kollagenen Zähnchén die Ursprungsstatte für die Tonofibrillen $a b$, so dass zwischen Epithel- und Bindegewebsfasern ein inniger Zusammenhang besteht, den er als Kontinuität bezeichnet. Ein solcher Ausdruck ist vom Standpunkt des Autors aus zulassig: denn wenn nach ihm in embryonaler Zeit zwischen Epidermis und Kutis eine Zone bestehen kann, die allmiiblich and ohne scharfe Abgrenzung in beide Schichten übergebt, so dass es nicht mehr möglich ist zu sagen, wo die Epidermis aufhört und die 
Kutis anfängt, so lässt sich vorstellen, dass hier fibrilläre Bildungen auftreten, die später zu einer Hălfte kollagene Fasern, zur anderen Tonofibrillen werden, und somit der Zusammenhang $z$ wischen kollagenen Fasern und Tonofibrillen auf den ursprünglichen Zustand einer einheitlichen faserigen Bildung znrückgehen würde. Dadurch bleibt aber unberührt, dass im fertigen $\mathrm{Zu}$ stand Tonofibrillen und kollagene Fasern ihrer chemischen und physikalischen Natur nachdurchaus verschiedene Dinge sind; hierfür sprechen nicht nur die bekannten Unterschiede in ihrem Färbungsverhalten, sondern auch polarisationsoptische Beobachtungen, über die ich anderswo berichten will $^{1}$ ). Gegenüber Krauss sehe ich die Ursache der innigen Verbindung von Tonofibrillen und kollagenen Fasern nicht in ibrer Genese aus einer einheitlichen Anlage, sondern in der funktionellen Leistung beider, die eine so imnige Verknüpfung verlangt. Den Ausdruck Kontinuität würde ich daher für diesen Zusammenhang nicht verwenden, sondern nur eine unmittelbare oder durch ein Kittmaterial bewirkte, dauerhafte Verbindung der beiderlei Faserarten annehmen. Übrigens ergeben ja unsere Beobachtungen, dass nur ein Teil der Tonofibrillen an der oberen Grenze des basiepithelialen Netzes ansetzt, die Mehrzahl dagegen, vor allem die mitten über den aufsteigenden Fasern gelegenen, mit den Fortsatzen der Epithelzellen in seine Maschen eintreten und somit nicht in einer eigentlichen direkten Verbindung mit lollagenen Fasern stehen.

\section{Die funktionelle Bedeutung des Aufbaues der Panzerhaut.}

Rufen wir uns noch einmal lurz die wichtigsten Züge der Architektur des unverknöcherten Panzers von Emyda ins Gedächtnis zurück, wie sie sich nach dem vorstehend Mitgeteilten ergaben.

Von den zwei Schichten der Lederhaut besitzt die aussere $B$ ündelschicht eine verwickelte, aber gesetzmässige Strultur: kräftige kollagene Bündel sind in mehreren Lagen übereinandergeschichtet, und zwar so, dass die bandartig abgeplatteten, auf der Kante stehenden Fasern in jeder Lage unter häufiger Gabelung und Anastomose ("geschlitzte Bindegewebsplatten") fast

1) Vgl. meine Abhandlung: Über den Nachweis der Epidermis-Tonofibrillen in polarisiertem Licht. Arch. f. Zellforschung, Bd. XVI. 
parallel, von Schicht zu Schicht aber rechtwinklig gekreuzt hinsichtlich der Schale im ganzen diagonal - verlaufen. Die einzelnen Bündellagen erstrecken sich jeweils nur über einen kleinen Abschnitt der Schale, indem sie schräg gegen die Epidermis ansteigen, derart, dass sie sich zum Rande der Schale hin dachziegelartig überdecken. Dabei beginnt eine jede Lage dünn an der Unterseite der Bündelschicht, nimmt langsam an Stärke zu und lâuft gegen die Epidermis hin wiederum verjüngt aus. Unter der Oberhaut tritt eine Lockerung des im übrigen sehr festen Gefüges der Bündelschicht ein. Die beschriebenen Lagen der Bündelschicht werden von senkrecht $\mathrm{zur}$ Epidermis auf steigenden Fasern durchsetzt, die in den schlitzartigen Spalten zwischen den anastomosierenden Bündein der einzelnen Lagen hindurchtreten. An der Grenze benachbarter „, horizontaler“ Schichten findet eine Aufspaltung der senkrecht verlaufenden Fasern statt, und indem die Gabeläste benachbarter Fasern sich verbinden (, $\mathrm{U}$ mbündelung $\left.{ }^{\prime \prime}\right)$, kommt es zur Bildung eines Raumgitters, dem die „horizontalen“ Bündel unverschiebbar eingelagert erscheinen. Die oberen Enden der senkrecht aufsteigenden Fasern vermitteln den $\mathrm{Zusammenhang} \mathrm{zw}$ ischen Epidermis und $\mathrm{Kutis:}$ sie dringen in die Oberhaut ein und liefern das basi e pi thelial e Netz, welches die Ausläufer der epidermalen Zylinderzellen in sich aufnimmt; diejenigen basalen Epidermiszellen, welche gerade über dem Ansatz einer aufsteigenden Faser sich befinden, sind durch starke Ausbildung von Tonofibrillen gekennzeichnet ("Ansatzzell en"). Auch die "horizontalen "Lagen der Bündelschicht gehen schliesslich, wenigstens zum Teil, in das basiepitheliale Netz ein. Die inuere, mächtige Lage der Lederhaut, die Filzschicht, besitzt keinen streng geregelten Faserverlauf; sie nimmt die unteren Enden der aufsteigenden Fasern und die hier auslaufenden Lagen der Bündelschicht in sich auf. An ihrer Unterfläche verdichtet sie sich zur Grenz$\mathrm{sch}$ ic $\mathrm{ht}$, die eine Andeutung von kreuzweiser Schichtung mehrerer. Faserlagen erkennen lässt.

Wenn wir nun versuchen, diese Architektur der häutigen Schale von Emyda in bezug auf ihre mechanische Bedeutung zu analysieren, so müssen wir uns zunächst einmal die biologische Aufgabe des Schildkrötenpanzers vergegenwärtigen. Bei den meisten erwachsenen Formen besteht er aus einer in 
ihrer ganzen Ausdehnung knöchernen Hülle, einem A ussenskelett, das die Form des Rumpfes bestimmt, den umschlossenen Weichteilen Halt, Muskeln Ansatzpunkte bietet und zugleich eine undurchdringliche, druckfeste Kapsel darstellt, die dem Besitzer ganz erbeblichen Schutz gegen mechanische Schidigungen verleiht, zumal Kopf und Beine darin aufgenommen werden können; vermögen doch schon verbältnismässig kleine Schildkröten beträchtliche Belastungen ohne Schaden zu ertragen. Bei diesen Leistungen treten die in den Hautpanzer aufgenommenen e n doskelettalen Stücke (obere Bögen und insbesondere Rippen) infolge ihrer schwachen Ausbildung bezw. Reduktion beim erwachsenen Tier zurück, wäbrend die Entwicklung der Hornschicht zu einer Schildpattlage eine weitere Festigung des Panzers bedeutet. Die Widerstandsfähigkeit des Panzers gegen Druck beruht aber nicht nur auf seinem Material (Knochen und Schildpatt), sondern auch auf seiner Form: die Rückenschale vol allem der Landschildkröten bildet eine $\mathrm{Kuppel}$, deren Druckfestigkeit durch die Verbindung mit dem einem Fundament (Widerlager) vergleichbaren Bauchschild noch weiterhin erhöht wird (vgl. betr. der Bedeutung von Form und Anordnung der einzelnen Knochenstücke Bienz 1895).

Der knöcherne Zustand des Panzer's wird aber erst allmählich im Laufe der Ontogenese erreicht, so dass bei allen jugendlichen Schildkröten mehr oder mínder grosse, von Bindegewebe erfüllte Lücken in ihm vorhanden sind. Diese bindegewebigen Anteile der Schale erhalten sich bei manchen w as serlebigen Formen, so auch den Trionychiden, zeitlebens in auffallend grossem Umfange, ja nehmen mit dem Grösserwerden der Schale in den absoluten Maßen zu; das muss als eine Rückbildung des knöchernen Panzers gelten, die offenbar im Zusammenhang mit der für das Leben im Wasser erwünschten Verminderung des spezifischen Gewichtes erfolgte. Somit wird die Schale der Schildkröten einerseits vorlä ufig aus Bindegewebe modelliert und nach und nach (mit zunehmendem Alter der Tiere) in Knochen ausgeführt, ähnlich wie die knorpelige Anlage des Endoskeletts der böheren Wirbeltiere durch Knochen ersetzt wird. Andererseits sehen wir auch das Bindegewebe als endgültiges Baumaterial, namlich als Vertreter des Knochens, fungieren. Dieser letzte Fall ist auch bei dem hăutigen An- 
teil des Panzers der erwachsenen Emyda gegeben, und die Frage nach der funktionellen Bedeutung seiner Architektur wird somit zunăchst dahin gehen, inwiefern sein Aufbau geeignet erscheint, ein Aussenskelett, eine formkonstante, druckfeste Kapsel zu schaffen, bzw. die vorhandenen knöchernen Elemente des Panzers in dieser Weise zu ergänzen. Dabei ist allerdings zu berücksichtigen, dass die Anforderungen an Druckfestigkeit bei den wasserlebigen Schildkröten nicht so weitgehend $z u$ sein brauchen wie bei landlebigen, und dass die Erzielung einer hohen Druckfestigkeit durch die Entwicklung einer hoch gewölbten Kuppel hier mit der Ausbildung einer für das Schwimmen geeigneten Panzerform konkurrieren muss.

Das wesentliche Bauelement des unverknöcherten Panzers, die kollagene Faser, erscheint an sich wenig geeignet als Skelettsubstanz; denn ihr physikalischer Charakter wird bekanntlich durch ihre enorme Zugfestigkeit (in Richtung der Faserachse) und geringe Biegungsfestigkeit bestimmt. Das Überwiegen der Zugfestigkeit über die Biegungsfestigkeit ist eine durchgehende Eigentümlichkeit fadenartiger Gebilde; lässt sich doch mittels eines Fadens, der unter seinem eigenen Gewicht zusammenknickt, eine weit erbeblichere Last ziehend von der Stelle bewegen. So findet sich denn die kollagene Faser vor allem dort im Organismus verwendet, wo $\mathrm{Zug}$ kräfte übertragen oder Widerstand gegen sie geleistet werden soll (Sehnen, Bänder). Doch gibt es auch Falle, in denen durch eine bestimm te Anordnung zugfester Elemente druckfeste Gebilde erzeugt werden, z. B. die Schwanzflosse des Delphins nach Roux (1895), bei der sogar ein Wechsel zwischen Biegsamkeit und Festigkeit in dieser Weise ermöglicht ist. Auch die mechanischen Eigenschaften der hautigen Schale von Emyda granosa werden durch eine bestimmte Anordnung der kollagenen Fasern erzielt.

Da nun die Panzerhaut aus einer Spezialisierung des gewöhnlichen Integuments hervorgegangen ist, so fragt es sich, welche Besonderheiten die Haut der Schale diesem gegenüber aufweist und wie hieraus ihre abweichenden Eigenschaften resultieren. Damit empfiehlt es sich, zunăchst einmal den $B$ au des gewöhnlichen Integuments mit Rücksicht auf seine Leistungen zu prüfen. 
Eine durchgreifende Eigentümlichkeit im Bau der Lederbaut der niederen Wirbeltiere ist die Anwesenheit mehrerer kreuzsch i chtiger Lage n, deren jede aus einer parallelfaserigen Schicht von leimgebenden Bündeln besteht, die in der Diagonalrichtung des Körpers ziehen, deren Faserrichtung aber von Schicht zu Schicht gegen $90^{\circ}$ gekreuzt ist, also eine Architektur, wie sie der Bündellage der Panzerhaut von Emyda in ausgesprochenster Form zukommt. Dieser Aufbau der Lederhaut wurde schon von $R$ at $h \mathrm{k}$ e bei verschiedenen Gruppen der niederen Wirbeltiere festgestellt und mehrfach ist auf seine mechanische Bedeutung hingewiesen worden. So sagt z. B. Biedermann (1914, S. 935): „Handelt es sich um bindegewebige Hãute und Membranen, welche dehnenden Kräften Widerstand leisten sollen und bei denen es auf besondere Festigkeit ankommt, so finden wir meist, wie bei den Faszien, zwei sich mehr oder weniger genau unter rechtem Winkel kreuzende Fibrillensysteme, wobei die einer Richtung angehörenden Bündel immer in. einer Schicht zusammenliegen ..... Diese Art der Anordnung findet sich namenlich in der Lederhaut." Als Beispiel hierfür zieht der Autor insbesondere die Kutis der Selachier heran und hebt die erstaunliche $\ddot{A}$ bnlichkeit ihres Faserverlaufs mit dem Aufbau gewisser Kutikularbildungen, namentlich des Chitinpanzers mancher Käfer, hervor.

Eine genauere mechanische Analyse eines hierher gehörigen bestimmten Falles, nämlich der $\mathrm{Ku}$ tis des Störs, hat aber meines Wissens nur Gebbardt (1914) unternommen. Die über $5 \mathrm{~mm}$ dicke Haut, welche den kreuzschichtigen Aufbau zeigt, ist durch eine grosse Geschmeidigkeit - sie stellt also gewissermassen ein Gegenstück zur Panzerhaut von Emyda dar - ausgezeichnet, die zunächst mit der grossen Dicke gar nicht zu harmonieren scheint Sie beruht auf der weitgehenden Verschiebbarkeit der einzelnen Lamellen der Kutis. gegeneinander, die nicht nur auf die Beförderung der Gleitungsmöglichkeit durch 'rechtwinklige Faserkreuzung einander berührender Flächen zurückzuführen ist, sondern auch auf die sparliche A usbildung senkrecht aufsteigender Bündel, die eine Verschieblichkeit in gewissen Grenzen zulăsst, während eine solche durch spitzwinklig von der Fläche einer Lamelle in die gegenüberstehende der anderen eindringende 
anastomosierende Bündel weit gründlicher aufgehoben würde. Die Geschmeidigkeit der Lederhaut infolge ihrer Zerlegung in einzelne, flächenhaft gegeneinander verschiebliche Lamellen, geht letzten Endes darauf zurück, dass der Widerstand eines gebogenen Körpersquadratisch mit seiner Höhe in der Biegungsebene wächst. Setzen wir etwa die Dicke eines Balkens $=a$, dann wäre sein Biegungswiderstand $a^{2}$. Zerlegt man nun den Balken durch einen Längsschnitt in der Mitte seiner Höhe in zwei Teile, so daß aus ihm zwei übereinanderliegende Balken, jeder von halber Höhe des ursprünglichen entstehen, so ist der Biegungswiderstand jedes derselben $=\left(\frac{a}{2}\right)^{2}$, der Biegungswiderstand beider zusammen $2\left(\frac{a}{2}\right)^{2}=\frac{1}{2} a^{2}$. D. h. "mit der Dicke der Lederbaut würde der Biegungswiderstand quadratisch wachsen, wenn sie nicht in einzelne flăchenhaft verschiebliche Lamellen zerlegt wäre. So stellt er nur die Summe der geringen Biegungswiderstände der relativ dünnen Einzellamellen dar. ${ }^{*}$

Gegen die Epidermis und den unteren Abschluss der Kutis hin werden die Einzelschichten der Lederhaut beim Stör ausserordentlich dünn und offenbar sehr fest, wohl wesentlich durch die aufsteigenden Faserbündel, miteinander vereinigt. Das erkilürt Gebhardt folgendermassen. Die aussere und innere Oberfläche der Lederhaut sind die Stellen des unmittelbaren Angriffes aller sie treffenden mechanischen Beanspruchungen. Derartiger Mannigfaltigkeit der Beanspruchung zu begegnen, gibt es nur das Mittel eines möglichst dichten Baues ohne wesentliche dimensionale Spezialisierung, d. h. also dichte Verfilzung bei faserigen Bauelementen; daraus resultiert hier der in klein eren Intervallen erfolgende Richtungswechsel der Bindegewebsbündel um $90^{\circ}$ und daraus die nach der Tiefe erst zu-, dann wieder abnehmende Dicke der Lederhautlamellen.

Dass die Hauptmasse der Fasern in der Lederhaut tang ential zur Körperoberfläche liegt, ergibt sich nach Gebhardt zunächst aus der gegenseitigen Spannung von $\mathrm{Haut}$ und Inhalt, bei der tangential gerichtete Fasern in ihrer Zugrichtung beansprucht werden; ferner daraus, dass drückende Beanspruchung der Oberfläche die Fasern senkrecht zu ihrer Längsachse, also in der gegen Druck am widerstandsfähigsten Dimension, trifft, während reibende Beanspruchung in Form der der Oberfiache parallelen Zugkomponente wiederum die 
Zugfestigkeit der Fasern in ihrer Längsrichtung in Anspruch nimmt.

Die Entstehung des regelmässigen $\mathrm{Faser} r \mathrm{chtungs-}$ we chsels um $90^{\circ}$ möchte Gebhardt (1914) auf dieselben Ursachen zurückführen wie die entsprechenden Verhältnisse in den Haversschen Lamellen des Knochens. Jede fertige Lamelle dient als Anlagerungsbasis für die nächste. Eine einmal gebildete Lamelle mit einheitlicher Faserrichtung besitzt dimensiona I verschiedene Elastizitätseigenschaften: sehr wenig dehnbar in der Faserrichtung, überaus elastisch quer zur Faserrichtung. Bei allen möglichen Insulten schwingt sie also mit grösstem Ausschlag quer zur Faserrichtung. Die neu gebildeten Fasern der nachsten Kage werden sich nun bestreben, sich in die Hauptschwingungsrichtung einzustellen, und so kommt es zur Faserkreuzung benachbarter Lagen (Gebhardt 1906, S. 311-315). Der schwierige Punkt der Bestimmung der Lamellendicke, bevor die Umsteuerung der Faserrichtung eintritt, erscheint beim Stö. durch besondere mechanische Verhältnisse gegeben.

Die diagonale Richtung des Faserverlaufs zur I. angsachse des Fisches ist nach Gebhardt (1914) von vornherein die wahrscheinlichste Richtung für die Oberfiachenbedeckung eines im Sinne der. Schwimmbewegungen sich stark deformierenden Körpers.

Fassen wir Gebhard ts Lrgebnisse der mechanischen Analyse der Lederhaut vom Stör nochmals kurz zusammen: 1. Die Geschmeidigke it der Haut beruht auf ihrer Zusammensetzung aus. zahlreichen dünnen Lamellen von geringer Biegungsfestigkeit, die sich bei Deformationen flächen haft gegeneinander verschieben können, was durch die sparliche Ausbildnng senkrecht aufsteigender Bündel begünstigt wird: 2 . die Anordnung der kollagenen Fibrillen ta ngential zur Kör'peroberfläche ist am geeignetsten im Hinblick auf die Beanspruchung der Haut durch Spannung. Druck und Reibung; 3. der diagonale Faserverlauf in den einzelnen Schichten gewährt den besten Zusammenhalt mit Rücksicht auf die Schwimmbewegungen; 4. die Entstehung der wechselseitigen Kreuzung der Faserung benachbarter Schichten kann entwicklungsgeschichtlich plausibel gemacht werden: sie erleichtert das Gleiten der Lamellen übereinander; 5 . die Abnalume der Schichtendicke gegen die Epidermis und die Unterseite der 
Kutis hin erklärt Geb hardt aus der maximalen und vielseitigen Beanspruchung dieser Partien der Kutis, die ein möglichst dichtes Gefüg e des Gewebes verlangt.

Die Ergebnisse $1-4$ lassen sich allgemein auf die $\mathrm{Haut}$ der Reptilien übertragen, soweit sie den kreuzschichtigen Bau aufweist, wie es bei Eidechsen, Schlangen, Krokodilen regelmässig der Fall ist. Allerdings ist hier die Dicke der Haut wohl selten so beträchtlich wie beim Stör und ihre Geschmeidigkeit daber nicht so erstaunlich; aber der tangential-diagonale Faserverlauf (hinsichtlich des diagonalen Verlaufs beachte man Schlängelbew egungen der genannten Reptilien, die an Stelle der Schwimmbewegungen beim Stör in Frage kommen), und die kreuzschichtige Anordnung der Fasern finden auch hier unter den oben erwähnten Verhältnissen ihre Erklärung. Eine Abnahme der Schichtendicke der einzelnen Lagen der Kutis lüsst sich in der Regel bei den Reptilien nur zur Epidermis bin feststellen, während die Kutis gegen die Subliutis hin unvermittelt mit derben Fasern abschliesst, und jedenfalls kann man für den oberen feinschichtigen Teil der Kntis (Subepidermis) nicht behaupten, dass el besonders fest gebaut sei, wie denn schon Leydig in der Lederhaut der Reptilien und Amphibien eine mittlere, aus einer Anzahl derber wagerechter Liagen bestehende Grundmasse und die beiden jenen nach oben and unten abschliessenden lockeren Grenzschichten (Subepidermis, Subkutis) unterschied. Sonderbarer Weise findet sich nun bei Emyda ein ähnliches Verhalten der kreuzschichtigen Lagen wie beim Stör nach Gebhardt, insofern jede einzelne Bündellage zur Epidermis und zur Filzschicht bin sich allmählich verjüngt, worauf ja früher schon nacbdrücklich bingewiesen wurde. Aber es soll bereits hier betont werden, dass der streng geregelte Verlauf der Bündel, also ihre dimensionale Anordnung, bis zur Epidermis reicht und, dass die der Epidermis benachbarten oberen Teile der Bündelschicht keineswegs fester, sondern lockerer gebaut sind als die tieferen Lagen (vgl. Fig. 7, Taf. XIII). Die unteren verjüngten Anteile der einzelnen Bündellagen zeigen dagegen keine Auflockerung. Auf diese Eigentümlichkeiten wird später noch genauer eingegangen werden.

Ehe wir in die Betrachtung der funktionellen Bedeutung der Einzelheiten der Panzerhaut von Emyda eintreten, sollen ein parr Worte uber die allgemeinen mechanischen Eigen- 
schaften der Filz- und Bündelschicht vorausgeschickt werden, soweit das nach Beobachtungen an fixiertem Material möglich ist. Schneidet man aus der Filzschicht ein würfelförmiges Stück heraus, wobei die Richtung der Flächen in bezug auf die Schale als Ganzes beliebig gewăhlt werden kann, so lässt es sich von allen Seiten her gleichmässig und ergiebig zusammendrücken. Dabei verbreitert es sich in der Richtung senkrecht zur wirkenden Kraft etwas, und es tritt eine geringe Menge Flüssigkeit (Alkohol) aus. Beim Aufheben des Druckes werden selbst starke Deformationen vollkommen ausgeglichen, wenn man nur dafür Sorge trügt, dass das Stückchen nicht austrocknet, am besten also den Druck unter Alkohol ausübt. Versucht man ein Stückchen der Filzschicht zu zerren, was an einem viereckig-prismatischen bequem auszufübren ist, so findet man, dass eine nur sehr geringfügige, von einer entsprechenden Gestaltsänderung begleitete Veriängerung eintritt. Nach diesen Versuchen zu śchliessen, sind die wesentlichen mechanischen Eigenschaften der Filzschicht geringe Widerstandsfähigkeit gegen Druck, hohe Zugfestigkeit und das Vermögen, erlittene Deformationen auszugleichen. Möglich, dass am lebendfrischen Material die Widerstandsfahigkeit gegen Druck etwas grösser ist als am fixierten; denn die gallertige Kittmasse, welche die Lücken im Filzwerk der Bindegewebsfasern erfült, dürfte sich schwerer verlagern als der dünntlüssige Alkohol, der grossenteils nunmehr an ihre Stelle getreten ist. Und dabei ist ja auch $\mathrm{zu}$ berücksichtigen, dass einem Austreten von Flüssigkeit aus der Filzschicht bei ihrem normalen Zusammenhang mit der Haut nach oben durch die Bündellage, rach unten durch die Grenzschicht der Ausweg versperrt ist.

Anders verbült sich die Bündellag e. Neben ausserordentlicher Zugfestigkeit (lederartiger Zähigkeit) besitzt sie auch eine erhebliche Widerstandsfähigkeit gegen Druck. Presst man ein Stückchen der Panzerhaut von seinen natürlichen Oberflächen her krăftig zwischen $z$ wei Objektträgern zusammen ${ }^{1}$ ), so lässt sich die Filzschicht auf die Halfte ihrer normalen Dicke, die Bündellage dagegen nur um weniger als ein Viertel zusammendrücken. Auch in der dazu senkrechten Ebene widersteht die Bündellage

1) Am einfachsten unter dem Binokularmikroskop zu beobachten nur für Messungen bietet das gewöhnliche Mikrosikop Vorteile. 
viel grösserem Druck als die Filzschicht; denn wahrend die letzte bedeutend an Dicke zunimmt, lässt sich die erste nicht entsprechend zusammenschieben, sondern legt sich bald in Falten, um der weitergehenden Deformation jener nachkommen zu können. Dass auch der Zusammenhalt der einzelnen Fasern in der Bündelschicht ein viel festerer ist als in der Filzschicht, verspürt man leicht aus dem erheblich grösseren Widerstand beim Einstechen von Nadeln.

Wie erklären sich diese verschiedenen Eigenschaften von Bündelschicht und Filzschicht aus ihrem Bau? Nach den früher geschilderten Befunden besteht die Fil zschicht aus welligen, nach allen Richtungen sich regellos durchflechtenden Bindegewebsfasern. Die reichliche Anwesenheit der Kittmasse zwischen den kollagenen Bündeln lässt es begreifen, dass trotz der bei dickeren Schnitten und unter schwächeren Vergrösserungen scheinbar grossen Dichte dieses Filzes die einzelnen Fasern ihre Verschiebbarkeit gegeneinander nicht ganz aufgegeben haben. Wirkt ein Zug auf die Filzschicht, so werden die annähernd in seine Richtung fallenden Fasern gestreckt, gehen aus welligem in gradlinigen Verlauf über. Daraus erklärt sich die Dehnbarkeit eines aus der Filzschicht geschnittenen Stückchens grösstenteils; denn bei weiterer Debnung muss die bekanntlich ausserordentlich geringe Debnbarkeit der kollagenen Fasern selbst in Anspruch genommen werden. Die Velfiluung der Fasern ist aber zu innig, als, dass der Filz sich unter der Wirkung. des Zuges in seine Bestandteile auflöste. Lässt der Zug nach, so werden sich die entstandenen Spannungen ausgleichen und das Hautstückchen wieder seine ursprüngliche Form annehmen. Dass ein regelloser Filz von Bindegewebsfasern keinen erheblichen Druckkrüften standhalten kann, so lange seine Fasern noch eine gewisse Verschiebungsmöglichkeit besitzen, ist selbstverständlich. Die Bewegungsfreibeit der Fasern gegeneinander ist aber nicht gross genug, als dass sie wälrend einer kurz dauernden Deformation eine neue Anordnung einnehmen könnten, welche die Spannungen ausgliche, die nunmehr senkrecht zur Richtung des Druckes entstanden sind. Daher kehrt nach dem Aufhören des Druckes das Hautstückchen wieder zur Ausgangsform zurück.

Die Bündelschicht unterscheidet sich von der Filzschicht 
hinsichtlich der hier ins Auge gefassten Besonderheiten nach zwei Richtungen hin: ihre Bindegewebsbündel verlaufen fast geradlinig und die Verschiebbarkeit derselben ist fast a ufgehoben. Schon aus dem ersten Grunde wird sie sich bei Zugbeanspruchung viel weniger dehnbar erweisen als jene, indem eine Verlängerung nur auf Kosten der Dehnbarkeit de1kollagenen Bündel selbst möglich ist.

Die Beseitigung der Verschiebbarkeit der B üıdel gegen einander erfolgt zunächst dadurch, dass ihre Verwebung ungemein dicht ist. Das äussert sich nicht nur in der minimalen Menge von Kittmasse, die zwischen ihnen nachweisbar ist, sondern auch in ihrer Form: die bandartige Abflachung der Bündel der "horizontalen" Lagen und der zwischen ihnen hindurch tretenden aufsteigenden Fasern muss doch als unmittelbarer Ausdruck ihrer gegenseitigen Pressung gelten. Ferner aber ist in den einzelnen Lagen der Bündelschicht die Möglichkeit des Aneinandervorbeigleitens benachbarter Bündel durch ibre zahllosen Anastomosen völlig aufgehoben; dieser Tatbestand rechtfertigt die schon oben angewandte Bezeichnung „Bindegewebsplatten mit schlitzförmigen Spalten in der Faserungsrichtung": Deformationen derartiger parallelfaseriger, geschlitzter Platten durch Kräfte, die in ihrer Ebene angreifen, werden in der Faserrichtung durch die Zugfestigkeit des Materials gehemmt und sind daher im vorliegenden Fall sehr geringfügig. Einem $\mathrm{Zug}$ in der Richtung senkrecht zur Faserung widerstrebt dagegen nur die geringe Biegungsfestigkeit der Fasern und eine Formänderung der Platte erfolgt, indem die Schlitze sich verbreitern. Dadurch aber, dass in der Bündelschicht mehrere dieser geschlitzten Platten mit rechtwinklig gekreuztem Fasernverlauf innig miteinander vereint sind (s. u.), wird eine derartige Deformation der Bündels ch icht im ganzen unmöglich.

Wie die Verschiebbarkeit der Bündel ein und derselben Lage durch ihre zahllosen Anastomosen aufgeboben ist, so wird die Gesamtheit der Lagen durch die aufsteigenden Fasern zu einem Ganzen vereinigt und damit scheerenden Kraften Widerstand geboten. Zwar möchte der senkrechte Verlauf dieser Elemente zunächst recht ungeeignet erscheinen, den verlangten $Z$ weck $z u$ erfüllen; denn wie Gebhardt (s.o.) 
zutreffend ausgeführt hat, würde eine Verschiebbarkeit benachbarter Lagen weit gründlicher durch solche Bündel aufgehoben, die spitz winkli g benachbarte Lamellen miteinander verknüpften. Aber durch die beschriebene , $\mathrm{Umb}$ ündlung ${ }^{\prime \prime}$ wird auch bei senkrecht aufsteigenden Fasern ein Üebereinandergleiten benachbarter Lagen verhindert, indem die Punkte der Umbündlung wie Knoten wirken, die benachbarte aufsteigende Fasern mit einander verbinden und so weder ein Abheben noch ein Gleiten der horizontalen Lagen gegeneinander erlauben. Im gleichen Sinne wirkt auch die grosse Zabl der senkrecht aufsteigenden Bündel.

Im Gegensatz zu Gebhardts Befunden beim Stör (s. o.) findet in der Bündelschicht von Emyda zur Epidermis hin zwar eine Abnahme der Lamellendicke, aber keine Festigung, sondern eine Auflockerung des Gefüges statt. Iieses Verhalten scheint mir ein Ablösen der Epidermis von ihrer Unterlage durch scheerende Kräte zu erschweren. Rubte das Stratum Malpighii einer vollkommen starren obersten Lage der Lederhaut auf, dann würden in der Epidermis-Kutisgrenze zwei Schichten von sehr verschiedener Konsistenz einander unmittelbar berühren und damit wäre eine scharf definierte Ebene geschaffen, in der bei scheerender Beanspruchung der Haut leicht Kontinuitätstrennung auftrăte. Dadurch aber, dass die aufgelockerten obersten Schichten der Bündellage schrittweise zu dem festen Gelüge ihrer tieferen Abschnitte überleiten, wird diese Gefahr vermindert.

Neben der Verknüpfung der Bündellagen besteht die Aufgabe der senkrecht aufsteigenden Fasern in der B efe stigung der Ep idermis a uf ihrer Unterlage. Wie das imeinzelnen geschieht, ist im Abschnitt über die Epidermis-Kutisverbindung erlâutert. Hier sei nur noch darauf hingewiesen, dass wir wohl annehmen können, dass die an die Epidermis ansetzenden aufsteigenden Fasern sich in einer gewissen Zugspann ung befinden; denn so allein wird es verständlich, dass die - von dem Zug in erster Linie betroffenen - Zellen der basalen Epidermisschicht, die in ihrer unmittelbaren Fortsetzung liegen, eine stärkere Ausbildung der Tonofibrillen zeigen, zu Ansatzzellen werden. Nach allgemeiner Anschauung sind es Wachtumsspannungen innerhalb der Epidermis, welche die Ausbildung der Tonofibrillen hervorrufen. Dass aber auch von der Kutis ausgehende Zugkräfte in gleichem Sinne wirken, 
wird am treftlichsten belegt durch das Auftreten von Bündeln von Plasmafasern in denjenigen basalen Zellen der Froschepidermis, an welchen glatte Muskelzellen ansetzen (vgl. W. J.S ch midt. $1918,1919,1920$ ).

Schliesslich vermitteln die aufsteigenden Fasern wenigstens zum Teil die Verbindung von Bündelschicht und Filzschicht, indem sie in die letzte ausstrahlen und sich mit ihrem Maschenwerk verweben.

Die dichte Lagerung der einzelnen Bündel in der Bündelschicht, ihre zahlreichen Anastomosen, die Kreuzung benachbarter Lamellen, die grosse Zahl der aufsteigenden Fasern und die Art ihrer Umbündlung, alles zielt darauf hin, jegliche Verschiebbarkeit der Bauelemente gegeneinander aufzuheben. So stellt den die Bündelschicht von Emyda gerade das Gegenteil der durch Gebhardt beschriebenen Haut. vom Stör dar. Schneidet man aus der Haut eines niederen Wirbeltieres mit typisch kreuzschichtigem Bau und diagonalem Faserverlauf ein viereckiges Stück aus, dessen Seiten der Quer- und Längsrichtung des Körpers parallel gehen, und übt nun einen $\mathrm{Zug}$ in der Längsrichtung aus, so wird das Stück länger, wobei der Kreuzungswinkel benachbartel Schichten kleiner wird, indem die Faserrichtung nach Möglichkeit sich in die Beanspruchungsrichtung einstellt; bei $\mathrm{Zug}$ in der Querrichtung werden die Stücke breiter, indem der Kreuzungswinkel sich vergrössert. Dicken Häten kommt neben dieser Deformationsmöglichkeit noch die gleitende Verschiebung übereinander gelegener Lamellen in merklicher Weise zu (vgl. oben Gebhardt). Weder das eine noch das andere ist bei einem ausgeschnittenen Stückchen der Bündelschicht von Emyda möglich. So wurde bei Emyda mit verbaltnismäsig geringen Modifikationen einer alt überkommenen Struktur ein Gewebe von ganz anderen mechanischen Eigenschaft en geschaffen.

Dadurch, dass ein Ausweichen der Fasern unmöglich geworden ist, besitzt die Bündelschicht eine erhebliche Druckfestigkeit. Wirkt der Druck senkrecht zur Fläche der Haut, so wird die Mehrzahl der Fasern senkrecht zu ihrer Längsrichtung beansprucht, also in der Dimension, in welcher ihre Druckfestigkeit am grössten ist, und die horizontalen Lagen im ganzen werden nur um so mehr zusammengepresst; scheerende Krafte bleiben 
wirkungslos, da sie nicht die einzelnen Lagen übereinander zu verschieben vermögen; Druck parallel der Hautfläche würde in Richtung der Faserung obne kreuzschichtige Anordnung erhebliche Deformation bervorrufen können; infolge derselben aber kommt er nicht zur Geltung; denn senkrecht zur Faserung ausgeübter Druck festigt nur den Zusammenhalt einer geschlitzten Platte.

Nachdem die vorstehenden Erörterungen Aufschluss über die mechanischen Eigenschaften der beiden Schichten der Panzerhaut gebracht haben, können wir nunmehr auf den Bau der Haut mit Rücksicht auf die Scbale als Ganzes eingehen.

Dass die widerstandsfähigere Bündelschicht die Aussen-und die Filzschicht die Innenlage der Schale liefert, erscheint auch abgesehen von der durch die Phylogenie gegebenen Anordnung dieser beiden Schichten (Bündellage $=$ Modifikation der Kutis, Filzschicht $=$ Ersatz der tiefer gelegenen, rückgebildeten Muskulatur) insofern zweckmässig, als dadurch vor Schädigungen mittels scharfer oder stumpfer Gewalt besser Schutz geboten wird; das letzte insbesondere, weil die Bündellage ja keineswegs aus sprödem Material besteht. Ferner ist aber auch zu berücksichtigen, dass Rücken- und Bauchschale infolge ihrer Wölbung bis zu einem gewissen Grad g eboge ne Platten darstellen, deren konvexe Seite das Maximum der Beanspruchung erleidet, weshalb hier die grösste Festigkeit der Struktur bestehen muss.

Die auffălligste Eigentümlichkeit der Panzerhaut von Emyda ist wohl die schräge Orientierung der einzelnen Lamellen der Bündelschicht in bezug auf die Schalenoberflache. Sie scheint mir die Bedeutung zu haben, die Wölbung von Rücken- und Bauchschale zu erhalten, bezw. ihrer Abflachung Widerstand zu leisten. Ist diese Annahme richtig, dann wäre die Schrăgstellung der Lamellen für die aus der Kuppelform der Schale resultierende bohe Druckfestigkeit von wesentlicher Bedeutung, soweit der unverknöcherte Randteil in Frage kommt.

Wie früher berichtet, sind die Iagen der Bündelschicht in bezug auf die ganze Schale so orientiert, dass ihre inneren Enden zur Wölbung der Schale, ihre äusseren dagegen zur Peripherie der Schale hinweisen (vgl. Textfig. D, S. 205). Denkt man sich nun in der beschriebenen Richtung und zwar nach dem 
Schaleninnern bin einen Zug ausgeübt, so wird er offenbar die Wölbung der Schale erhöhen, wie ein Blick auf Textfig. Ha ohne weiteres erkennen lässt. Nun geht $z$ war von den Lagen der

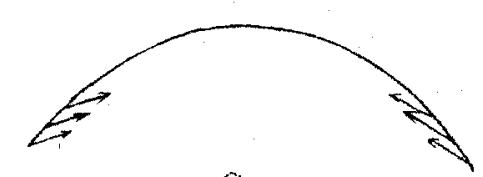

Bündelschicht kein aktiver Zug aus, aber wenn von aussen her auf die Schale ein Druck wirkt, der sie abtlachen würde, dann widersetzen sich die schräg gestellten Lagen diesem Bestreben.

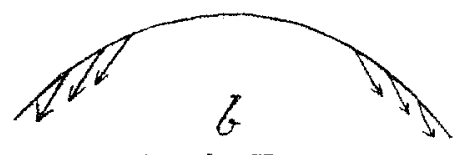

Textfig. H.

Sehema zur Erläuterung der funktionellen Bedeutung der schrägen

Orientierung der Bündellagen. Dass die schräge Orientierung der Bündellagen, so wie sie in der Schale vorliegt, einen derartigen Effekt hervorrufen muss; wird vor allem klar, wenn man sich einmal vorstellt, dass die Neigung der" Schichten (bei im übrigen gleichen Winkel zur Oberfiche) eine entgegengesetzte ware (Textfig. $\mathrm{Hb}$ ). Unter solchen Umstanden würden sie durch einen Aussendruck nicht in Spannung versetzt und waren daher unfäbig, ilım zu widerstehen. Im Schema. T'extfig. $\mathrm{Ha} u$. b, ist der Neigungswinkel der Lamellen der Bündelschicht gegen die Schalenoberfläche grösser angenommen als in Wirklichkeit. Seine Grösse ist selbstverstandlich nicht ohne EinHuss auf die quantitative Leistung eines solchen Systems; hier kam es aber nur darauf an, eine Vorstellung von der A t: seiner Funktion zu gewinnen.

In diesem Zusammenhange müssen wir auch nochmals der Filzschicht gedenken; nimmt sie doch die inneren Enden der Lamellen der Bündellage in sich auf und dient so ilrer Verankerung. Denkt man sich die schrägen Lamellen nach dem Innenraum der Schale bis zu ihrem Schnittpunkt weiter fortgesetzt, so würde ein Fasersystem entstehen, das sich funktionell einigermassen den Verstrebungen vergleichen liesse, die das Innere einer Kuppel durchsetzen und durch wesentlich radiale Zugwirkungen ihre Festigkeit erhöhen. Wird ein solches System nicht vollkommen, sondern nur anf seiner Peripherie ausgeführt, so muss für eine sichere Verankerung der zentralwärts weisender Enden desselben gesorgt werden. Diesen Dienst leistet wohl für die Lamellen der Bündelschicht die Filzlage. 
Ich halte es auch nicht für ausgeschlossen, dass die schräge Orientierung der Lamellen für die Bewegung der Klappen des Bauchschildes (s. Einleitung und vgl. Textfig. D) eine Rolle spielt und wenigstens zum Teil einen automatischen Ablauf dieses Vorganges bewirkt, indem ein Öffnen dieser Klappen durch Ausstrecken der Hinterbeine einer aktiven Verminderung der Wölbung des Bauchschildes gleichkommt, die sich beim Schliessen von selbst wieder ausgleicht.

Dass die Faserung der kreuzschichtigen Lagen in der Diagonalrichtung der Schale verläuft, wird wohl an erster Stelle auf die Vererbung einer gegebenen Struktur bezw. auf entwicklungsmechanische Momente zurückzuführen sein. Denn ich stimme Gebhardt (s. o.) darin vollkommen zu, dass dieses Verhalten mit den Deformationen des Körpers bei (Schwimmund Schlangel)bewegungen in Zusammhang $\mathrm{zu}$ bringen ist und dass unter solchen Umständen eine derartige Anordnung der Fasern für die Oberflachenbedeckung als günstigste erscheint. Man stelle sich nur einmal vor, die Faserrichtung in den gekreuzten Lagen verliefe zirkulär und längs. Dann würden bei Schlangelbewegungen an den konvex geformten Krümmungen des Körpers die längsziehenden Fasern der notwendigen Dehnung der Haut widerstreben, die zirkulären dagegen auseinander zu weichen trachten. Bei zur Körperachse diagonaler Faserrichtung dagegen wird unter den gleichen Umständen durch Veränderung des Kreuzungswinkels der Schichten (s.o.) die nötige Dehnung der Haut erzielt, obne dass das Bestreben einer Kontinuitătstrennung in einer der Kreuzungsrichtungen entstünde. Die grundsätzliche Richtigkeit dieser Überlegungen findet auch wohl darin eine Stütze, dass der kreuzschichtige Bau der Lederhant nur den niederen Wirbeltieren zukommt, bei denen starke Achsenbiegungen des Rumpfes für die Fortbewegung eine Rolle spielen; mit dem Fehlen solcher Bewegungen bei Vögeln und Säugern sehen wir auch den kreuzschichtigen Bau der Haut schwinden. Da nun aber die Schale von Emyda ein starres Gebilde darstellt, lässt sich vom Boden der vorstehenden Überlegungen aus keine funktionelle Erklärung für den Faserverlauf der kreuzschichtigen Lagen in der Diagonalrichtung des Körpers geben.

Die bisherigen Erörterungen waren wesentlich der Bündelschicht gewidmet, wenngleich wir an einzelnen Stellen schon auf 
die Filzschicht zurückgreifen mussten, in der wir die $\mathrm{Ver}$ ankerungstelle der aufsteigenden Fasern und auch der schräg orientierten Lagen der Bündelschicht erblickten. Der im wesentlichen einheitliche Bau der Filzschicht bietet auch nur wenige Anbaltspunkte $z u$ ins einzelne gehenden Erwägungen über ihre funktionellen Leistungen. Die Grenz$\mathrm{schicht}$, die dichtere Lage an ihrer Innenseite, hat offenbar die Bedeutung, den von in n e $n$ her die Schale treffenden mechanischen Beanspruchungen Widerstand zu leisten; sie stellt somit ein gewisses Analogon zur Bündellage dar, der sie ja auch im Bau ähnelt. Da normalerweise die Beanspruchung der inneren Schalenfläche viel weniger intensiv ist als jene der äusseren, so kann hier schon eine verhältnismässig dünnere Lage den gewünschten Dienst tun.

Berücksichtigt man die früher auseinandergesetzte geringe Druckfestigkeit der Filzschicht, so kann ihr an sich als Skelettmaterial gegenüber der Bündellage nur untergeordnete Bedeutung zugesprochen werden. Sie stellt ein zäbes F üllmaterial dar, das die beiden festeren, äusseren und inneren Schichten (Bündel- und Grenzschicht) zu einem Ganzen verknüpft und durch seine Elastizitat sehr geeignet erscbeint, lokale Insulte, welche die Schale von aussen trefien, aufzunebmen, zu dümpfen und unschädlich zu machen. Dabei ist nicht zu vergessen, dass dieses Füllmaterial durch seine Einlagerung zwischen festen Schichten, die der in ihm reichlich vorbandenen, halbflüssigen inkompressiblen, interfibrillaren Kittmasse den Ausweg versperren, selbst an Festigkeit gewinnt und damit die Leistungsfabigkeit der Schalenhaut als Ganzes steigert.

\section{Literaturverzeichnis.}

1. Bie dermann, W., 1914: Physiologie der Stütz- und Skelettsubstanzen, in: Handb. vgl. Physiol., herausg. v. Winterstein. III. Bd., I, 1. Jena.

2. Bienz, A., 1895: Dermatemys Mavii Gray. Inaug.-Diss. Philos. Fak. Basel (auch in Revue Suisse de Zoologie, vol. III, p. 61).

3. Ficalbi, E., 1889: Osservazioni sulla istologia della pelle dei rettili cheloniani, in: Atti della R. Accademia dei Fisiocritici, Serie IV, vol. I.

4. Ge bhardt, C., 1906: Über funktionell wichtige Anordnungsweisen der feineren und gröberen Bauelemente des Wirbeltierknochens. II. Spezieller Teil. 1. Der Bau der $\mathrm{H}$ a ve r s schen Lamellensysteme und seine funktionelle Bedeutung, in: Arch. f: Entwicklungsmech., Bd. 20, S. 187. 
5. Derselbe, 1914: Einige mechanisch interessante Bindegewebsstrukturen, in : 28. Verh. Anat. Ges.

6. Goette, A., 1899: Über die Entwicklung des knöchernen Rückenschildes (Carapax) der Schildkröten, in : Zeitschr. f. wiss. Zool., Bd. LXVI, S. 407 .

7. Hertwig, 0., 1874: Über Bau und Entwicklung der Placoidschuppen und der Zähne der Selachier, in: Jen. Zeitschr. N. F., Bd. 1, S. 331.

8. H of $\mathrm{fm} a \mathrm{n}$, C. R., 1878: Beiträge zur vergl. Anatomie der Wirbeltiere, in: Niederl. Arch. f. Zool., Bd. IV, 2. u. 3. Heft.

9. Derselbe, 1890: Reptilien, in: Bronns Klassen und Ordn. des Tierreichs., VI. Bd., III. Abt., I. Schildkröten.

10. Krauss, F, 1906: Der Zusammenhang zwischen Epidermis und Kutis bei Sauriern und Krokodilen, in: Arch. f. mikr. Anat., Bd. 67, S. 319.

11. L w off, 1885: Beiträge zur Histologie der Haut der Reptilien, in: Bull. de la société des naturalistes de Moscou, année 1884, p. 313.

12. Rathke, H., 1848: Über die Entwicklung der Schildkröten. Braunschweig.

13. Roux, W., 1895: Gesammelte Ablandlungen über Entwicklungsmechanik der Organismen. I. Bd. Leipzig.

14. Schmidt, W. J., 1910: Das Integument von Voeltzkowia mira Bttgr., in: Zeitschr. f. wiss. Zool., Bd. XCIV, S. 611.

15. Derselbe, 1912: Studien am Integument der Reptilien. I. ebendort, Bd. CI, S. 139.

16. Derselbe, 1913; Dasselbe IV, in: Zool. Jahrb., Bd. 36, Abt. f. Anat., S. 377.

17. Derselbe, 1914: Dasselbe V, ebendort, Bd. 38, Abt. f. Anat., S. 1.

18. Derselbe, 1917: Die Chromatophoren der Reptilienhaut, in: Arch. f. mikr. Anat., Bd. 90, Abt. I., S. 98.

19. Derselbe, 1918: Über die Beziehungen der glatten Muskelzellen in der Haut vom Laubfroseh zum Epithel, in: Anat. Anz., Bd. 51. S. 289.

20. Derselbe, 1919: Sind die Muskelzellen in den perforierenden Bündeln der Haut bei Rana ektodermalen-Ursprungs?, ebendort, Bd. 52, S. 115.

21. Derselbe, 1920: Die Ontogenie der glatten Muskelzellen in der Froschhaut, ein Beispiel für die Differenzierıng der Epidermis durch Muskelzug, in: Zeitschr. f. allg. Physiol., Bd. XVIII, S. 317.

22. Derselbe, 1920: Über Schuppenrudimente und Hautsinnesorgane bei Emyda granosa, in: Zool. Anz, Bd. LII, S. 11.

23. Derselbe: Über den Nachweis der Epidermis-Tonofibrillen (bei Emyda) in polarisiertem Licht, erscheint im Arch. f. Zellforschung, Bd. XVI.

24. Verșluys, J, 1914: Über die Phylogenie des Panzers der Schildkröten und über die Verwandtschaft der Lederschildkröte (Dermochelys coriacea), in: Palaeontolog. Zeitschr., Bd. I, S. 321. 


\title{
Erklärung der Abbildungen auf Tafel XIII und XIV.
}

\section{Tafel XIII.}

\author{
Faserverlauf in der $r_{s}$ ederhaut.
}

Alle Abbildungen sind nach meist ungefärbten und dann bei engen Beleuchtungskegeln beobachteten Schnitten durch die unverknöcherte Haut der Schale von einer $13, \check{c} \mathrm{~cm}$ langen $\mathrm{Emyda}$ granos a unter Benutzung des Abbeschen Zeichenapparates hergestellt (Entfernung der Zeichenfläche von der Austrittspupille des Mikroskops $=250 \mathrm{~mm}$ ).

Für alle Figuren gilt: $\mathrm{B}=$ Bündelschicht

$$
\begin{aligned}
& \mathrm{E}=\text { Epidermis } \\
& \mathrm{F}=\text { Filzschicht } \\
& \mathrm{G}=\text { Grenzschicht } \\
& \mathrm{L}=\text { längsgetroffene Bündel } \\
& \mathrm{Q}=\text { quergetroffene Bündel. } \\
& \mathrm{S}=\text { senlrecht aufsteigende Fasern }
\end{aligned}
$$

Fig. 1. Diagonaler Querschnitt der Rückenhaut: Bündelschicht und angrenzender Teil der Filzschicht. In den tieferen Lagen der Epidermis kleine Melanophoren; in dem anstossenden lockeren Teil der Bündelschicht stärkere Anbäufung der kutanen Melanophoren; zwischen ihnen, dicht unter der Epidermis, die schwach ausgebildete Lage der Guanophoren. Die Lagen der Bündelschicht abwechselnd quer und längs getroffen. Ungefärbter Schnitt. Ze iss' Apochromat $16 \mathrm{~mm}$ und Komp.Okular 4. Vergr. $62: 1$.

Fig. 2. Diagonaler Querschnitt der Bauchhaut: Bündelschicht und angrenzender Teil der Filzschicht: Unter der Epidermis die krüftig entwickelte Guaninlage. Die Lagen der Bündelschicht steigen deutlich von links nach rechts an; die unterste (längsgetroffene) Lage läuft sich verschmälernd nach links hin aus; die oberste (unmittelbar unter der Guaninschicht gelegene) endigt sich verjüngend nach rechts hin. Im übrigen vgl, unter Fig. 1. Ungefürbter Sehnitt, Optik wie in Fig. 1. Vergr. 62: 1.

Fig. 3. Diagonaler Querschnitt durch den oberen Teil der B ünde Ls chicht Bauchhaut. Guanin durch Behandeln mit Ammoniakwasser entfernt/. Man beachte die lockere Lage der längs- und quergetroffenen Bündel nahe der Epidermis (in dieser Zone sind auch Querschnitte von Gefässen V sichtbar, ferner das Verhalten der aufsteigenden Fasern und ihre Beziehung zur Epidermis. Ungefärbter Schnitt (die Kerne sind nach Lage, Häufiglieit und Form unter Zugrundelegen gefärbter Präparate schwarz schematisch eingetragen). Zeiss Apochromat $8 \mathrm{~mm}$ und Komp-Okular 8. Vergr. 250:1. 
F ig. 4. Diagonaler Querschnitt durch den mittleren Teil der Bün dels c hich t (Rückenhaut): System der senkrecht aufsteigenden Fasern und sein Verhalten in der Höhe quer ("Kantenansicht ${ }^{*}$ ) und längs getroffener Bündellagen („„) Flächenansicht “, „Umbündlung“). Technik und Optik wie in Fig. 3. Vergr. 250:1.

Fig. 5. Diagonaler Querschnitt durch die unterste Lage der Bündelschicht und den angrenzenden Teil der Filzschicht (Bauchhaut): Ausstrahlen der senkrecht aufsteigenden Fasern in die Filzschicht. Technik und Optik wie in Fig. 3. Vergr. 250:1.

Fig. 6. Diagonaler Querschnitt durch die Grenzschicht der Rückenhaut. Ungefärbter Schnitt. $Z$ eis s' Apochromat $16 \cdot \mathrm{mm}$ und Komp.-Okular 4. Vergr. $62: 1$.

Fig. 7. Horizontalschnitt durch die Bündellage nahe der Epidermis (Bauchhaut). Zwei sich rechtwinklig kreuzende Lagen der Bündelschicht sind im Schnitt enthalten: innerhalb jeder Lage gabeln die Bündel sich und verschmelzen miteinander; die senkrecht aufsteigenden Fasern (von rundlichem Durchschnitt) sind quergetroffen. Schnittdicke 15, "Färbung Eisenhämatoxylin und Säurefuchsin; Zeis $\mathrm{s}^{2}$ Apochromat $8 \mathrm{~mm}$ und Komp-Okular 8. Vergr. $250: 1$.

Fig. 8. Horizontalschnittdurch denmittleren Teil der Bündel $\mathrm{sch}$ icht (Rückenhaut). Nur eine Lage von Bündeln ist im Schnitt enthalten, die sich vielfach gabeln und verschmelzen. Die dicht aneinander stehenden, senkrecht aufsteigenden Fasern erscheinen (bandartig abgeplattet) quer getroffen in den Spalten zwischen den Bündeln. Ungefürbter Schnitt. Optik wie in Fig. 7. Vergr. $250: 1$.

Fig. 9. Horizontalschnittdurch den untersten Teilder Bündelschicht und den angrenzenden der Filzschicht. Links zwei sich kreuzende Lagen der Bündelschicht in Schnitt enthalten, deren eine nach rechts in die Filzschicht ausstrahlt; in diesem ïussersten Teil der Filzschicht melirfach Gefüsse (V) und Nerven (N) getroffen. Ungefïrbter Schnitt. $\mathrm{Z}$ e is s' Apochromat $16 \mathrm{~mm}$ und Komp.-Okular 4. Vergr. 62:1.

Fig, 10. Orthogonaler Querschnitt durch den mittleren Teil der $B$ ündelschicht (Bauchhaut): Alle Bündellagen sind schrär getroffen; man beachte das Verhalten der senkrecht aufsteigenden Fasern. Schnittdicke $15 \mu$, Färbung Eisenhämatoxylin uni Säurefuchsin; Zeis s' Apochromat, $8 \mathrm{~mm}$ und Komp-Olvular 8. Vergr. $250: 1$.

\section{Tafel XIV.}

Epidermis und Epidermis-Kutisverbindung.

Alle Abbildungen sind unter Benutzung des Abbeschen Zeichenapparates hergestellt. (Entfernung der Zeichenfläche von der Austrittspupille des Mikroskops $=250 \mathrm{~mm}$.) Die Präparate stammen, sofern nichts anderes angegeben, von der Panzerhaut einer $13, \overline{\mathrm{cm}}$ langen $\mathrm{Em} \mathrm{m} d \mathrm{a}$ granos a. 
Fig. 11. Querschnitt durch die Epidermis des Bauchschildes. Horn$\mathrm{schicht}$ fein horizontal gestreift; in der basalen Zellschicht des Stratum Malpighi i die schlanken dunkler erscheinenden Kerne der Ansatzzellen kenntlich;. am Unterrand der Epidermis als schmale dunkle Zone das basiepitheliale Netz sichtbar, aus dem die aufsteigenden Fasern hervorgehen. Färbung Del a fields Hämatoxylin und Pikrinsäure-Säurefuchsin nach $v$ a n Gieson. Zeis' Apochromat $8 \mathrm{~mm}$ und Komp.-Okular 8 . Vergr. $250: 1$.

Fig. 12. Desgl. aber mit Eisenhämatoxylin gefärbt. Hornschicht tief schwarz; im Stratum Malpighii Zellbrücken, in seiner basalen Schicht die infolge der starken Ausbildung von Tonofibriller stark geschwärzten Ansatzzellen sichtbar; basiepitheliales Netz und Ansatykegel der aufsteigenden Fasern. Optik wie bei voriger Abbildung. Vergr. 250:1.

Fig. 13. Flachschnitt durch die basale Zylinderzellenschicht der Epidermis vom Bauchschild. Verteilung der AnsatzzellenFärbung, Optik wie in Fig. 12. Vergr. 250:1.

Fig. 14. Zellgruppen aus einem Flachschnitt wie in Fig. 13. Ansatzz ellen kräftig gefärbt, von geringem Querschnitt; in ihrer Peripherie die quer gretroffenen Tonofibrillen als dunkle Punkte; alle Zellen durch Brücken miteinander verbunden. Färbung Eisenhämatoxylin und Eosin. Z e iss' Apochromat $2 \mathrm{~mm} \mathrm{N.} \mathrm{A.} \mathrm{1,30}$ und Komp.-Okular 8. Vergr. 1000:1.

Flg. 15. Ähnliche Zellgruppe wie in der vorhergehenden Abbildung (aber aus der Epidermis des Rückenschildes). In der Peripherie aller Zellen die Querschnitte der Tonofibrillen sichtbar; Ansatzzellen durch Übergänge mit den gewöhnlichen basalen Zylinderzellen verbunden, Zell brücken. Färbung, Optik wie in Fig. 14. Vergr. $1000: 1$.

Fig. 16. Aus einem Querschnitt der Lippenepidermis: einige Zellen der mittleren Zone des Stratum Malpighii, durch weite Interzellularlücken voneinander getrennt, die ron zarten, mit $\mathrm{Kn}$ öt che $\mathrm{n}$ versehenen $\mathrm{Zellbr}$ i c ke $\mathrm{n}$ durchsetzt werden. In den Zellen Tonofibrillen, die sich stellenweise bündelartig durch mehrere Zellagen hindurch verfolgen lassen; die auf diese Bündel entfallenden Brücken und Knötchen sind besonders kräftigg ausgebildet. Färbung Eisenhämatoxylin. $Z$ e i s s' Apochromat $2 \mathrm{~mm}$ N. A. 1.40 und Komp.-Okular 8. Vergr. $1000: 1$.

Fig. 17. Flächenansicht einer Zelle aus den mittleren Lagen des Stratum Malpighii, IEpidermis der Rückenschale). Am Rande Zellbrücken, im Innern die To nofibrillen im optischen Querschnitt, besonders deutlich um den Kern herum ausgebildet; im Plasma bläschenförmiger Einschluss. Färbung Eisenhämatoxylin, Optik wie bei Fig. 14. Vergr. 1000: 1. 
Fig. 18. Zweikernige Zell e von gleicher Herkunft wie Fig. 17. Färbung, Optik wie bei Fig. 14. Vergr. 1000:1.

Fig. 19. Flächenansicht von drei Zellen aus den oberen Lagen des Stratum Malpighii (Epidermis der Bauchschale), bei zweien derselben ist auf das Innere des Zelleibes eingestellt, bei der dritten auf die von Zellbrücken übersäte Oberfäche. Färbung, Optik wie bei Fig. 14. Vergr. 1000:1.

Fig. 20. Flächenansicht von drei Zellen aus den obersten Lagen des Stratun Malpighii (Epidermis der Bauchschale). Kerat ohyalinkörner. Färbung, Optik wie bei Fig. 14. Verg. 1000:1.

Fig. 21. Zwei Zellen aus dem Übergangsgebiet von dem Stratum Malpighii zur Hornschicht (Querschnitt der Lippenhaut). Horizon t a le Anordnung der Tonofibrillen in den Zellen, deren Zusammenhang mit den Interzellularbrücken stellenweise kenntlich ist. Färburg Eisenhämatoxylin, $\mathrm{Z}$ e is s' Apochromat $2 \mathrm{~mm} \mathrm{~N}$. A. 1,40 und Komp.-Okular 8. Vergr. $1000: 1$.

Fig. 22. Querschnitt der Hornschicht und der anliegenden Lagen des Stratum Malpighii. Die Zellbrücken bleiben in der ganzen Horn. schicht erhalten, sind auch auf ibrer Aussenfläche sichtbar. Färbung, Optik wie bei Fig. 14. Vergr. 1000:1.

Fig. 23. Elächenansicht einer in Verhornung begriffenen Zelle der Lippenepidermis. Die Tonofibrillen umziehen (horizontal gelagert), zu dickeren Bündeln verklebt, allseits den Kern. Färbung Eisenhämatoxylin-Eosin, Z eiss' Apochromat $2 \mathrm{~mm} \mathrm{N.} \mathrm{A.} 1.40$ und Komp.-Okular 8. Vergr. $1000: 1$.

Fig. 24. Teil der Flächenansicht einer Hornzelle der Lippenepidermis Tonofibrillen im Zellinnern nicht mehr färbbar. Färbung. Optik wie bei voriger Abbildung. Vergr. 1000:1.

Fig. 25. Epidermis-Kut is verbindung (Bauchschild). Die aufsteigenden Fasern liefern dureh ihre Verzweigng das basiepitheliale Netz, das die unteren Enden der Zylinderzellen umfasst. Färbung Eisenhämatoxylin (stark differenziert) und Pikrinsäure-Säurefuchsin nach van Gieson. Optik wie in Fig. 14. Vergr. 1000: 1.

Fig. 26. Einzelne basale Zylinderzellen der Epidermis; die Striche markieren die Lage des basiepithelialen Netzes. a und b die unteren Enden der Zellen werden von den Maschen des basiepithelialen Netzes hülsenartig umfasst; c. u. d Beziehung der Netzmaschen zu den Tonofibrillen, e-g Zellen mit kräftig ausgebildeten Tonofibrillen, die in die Zone des basiepithelialen Netzes bineinreichen. Färbung Eisenhämatoxylin allein (e, f, g) bezw. kombiniert mit Pikrinsäure-Säurefuchsin. Z e is s' Apochromat $2 \mathrm{~mm}$ N. A. 1.40 und Komp.-Okular 8. Vergr. $1000: 1$.

Fig. 27. Basiepitheliales Netz im Flachschnitt der Epidermis (Bauchschild); die Maschen entsprechen den unteren Enden der basalen Zylinderzellen. Färbung Eisenhämatoxylin und Säurefuchsin, Z e i ss' Apochromat $2 \mathrm{~mm}$, N. A. 1.30 und Komp. Okular 8, Vergr. $1000: 1$. 
246 W. J. Schmidt: Die Panzerhaut der Weichschildkröte Emyda granosa.

Fig. 28. Beziehung des basie pithelialen Netzes zu den der Epidermis nächst gelegenen $\mathrm{F}$ as ernder horizontalen Bündel. Färbung, Optik wie in voriger Abbildung. Vergr. 1000:1.

Fig. 29. Basiepitheliales $N$ etz (Rückenschale): Fortsätze der basalen Zellen von den Querschnitten der Tonofibrillen umsäumt. Färbung Eisenhämatoxylin-Eosin, Optik wie in Fig. 27. Vergr. 1000:1.

Fig. 30. Basiepitheliales Netz sehr nahe der Koriumgrenze getroffen: Netzbalken breiter als die von ihnen umschlossenen Zellfortsätze. Färbung, Optik wie in Fig. 29. Vergr. 1000:1.

Fig. 31. Querschnitt durch den A $\mathrm{s} a \mathrm{t} \mathrm{z} \mathrm{k}$ egel einer senkrecht aufsteigenden Faser, in dem noch einige Durchschnitte von Tonofibrillen sichtbar sind. Färbung, Optik wie in Fig. 29. Vergr. 1000:1.

Fig. 32. Flachschnitt durch die Bündellage unmittelbar unter der Epidermis: zwei aufsteigende Fasern im Querschnitt. Färbung, Optik wie in Fig. 29. Vergr. 1000:1 (vgl. Fig. 7, Taf. XIII).

Fig. 33. Fil zschicht einer jungen Emyda granosa: kollagene Fasern durch reichliche interfibrilläre Kittmasse (Mucin) geschieden; in der letzten die Z ell en (Fibroblasten). Färbung Delafields Hämatoxylin-Eosin. Optik Zeiss' Apochromat $2 \mathrm{~mm}$. N. A. 1.30 und Komp.-Okular 4. Vergr. $500: 1$.

Fig. 34. Fibroblast aus der Haut der Unterlippe einer $3, \overline{0} \mathrm{~cm}$ langen Emyda granosa. Dem Kern angelagert ein Diplosom. Färbungr Eisenhämatoxylin. Optik Zeiss' Apochromat $2 \mathrm{~mm} \mathrm{N.} \mathrm{A.} 1.30$ und Komp.-Okular 8. Vergr. 1000:1. 


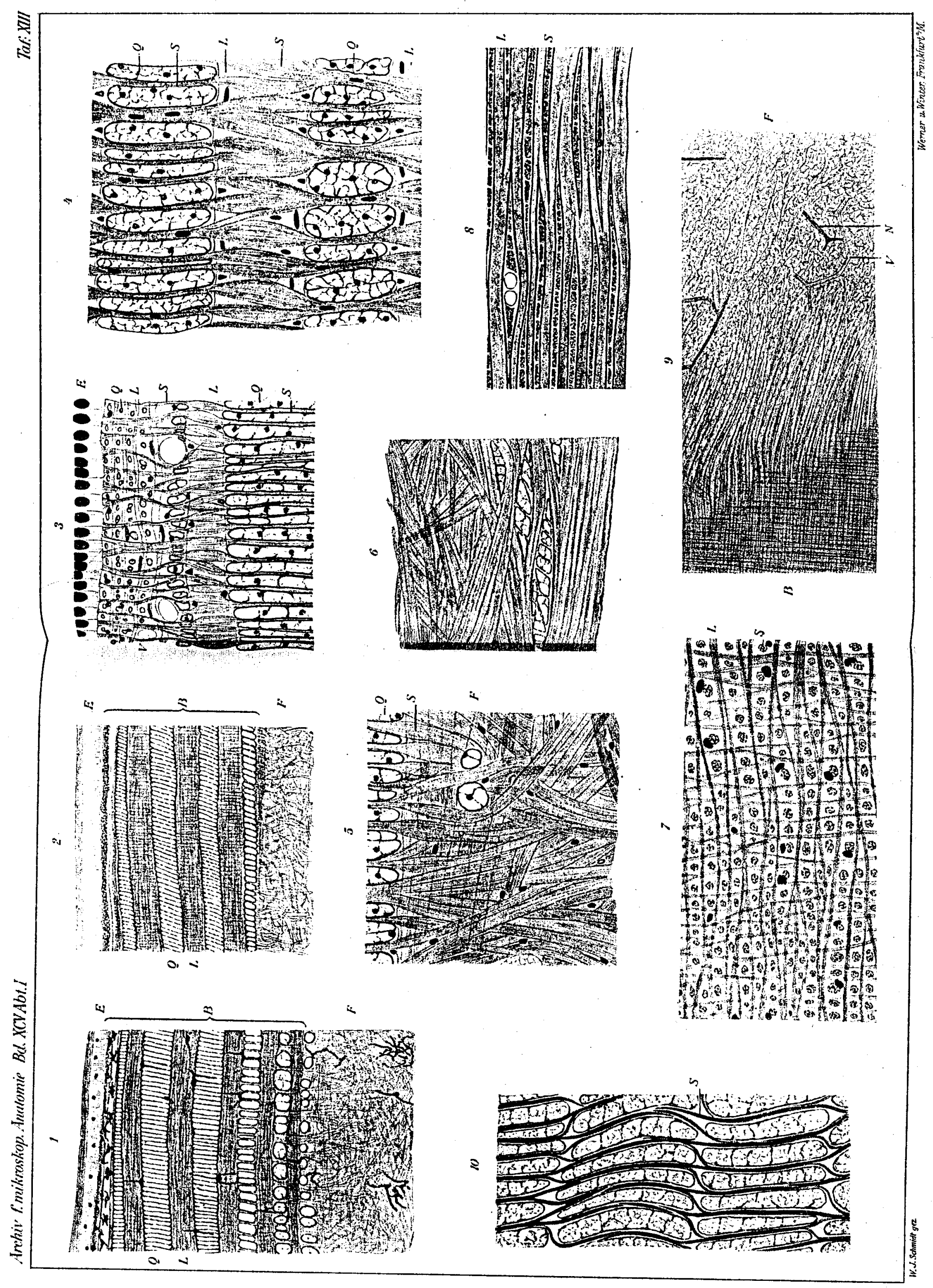




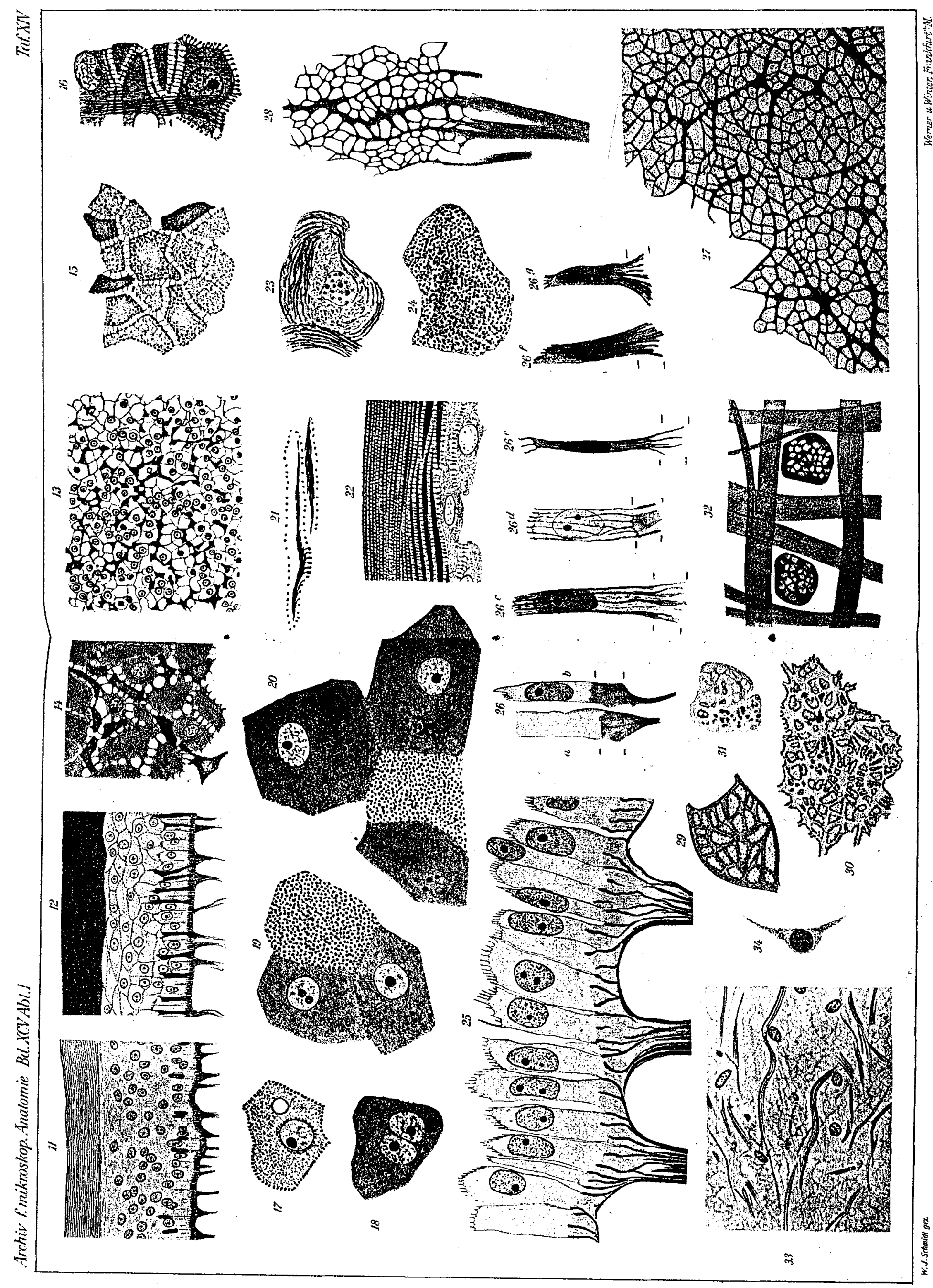

